\title{
Review Article \\ Lung Volume Reduction Surgery for Emphysema Treatment: State-of-the-Art and Perspectives
}

\author{
Eugenio Pompeo ${ }^{1,2}$ \\ ${ }^{1}$ Department of Thoracic Surgery, Policlinico Tor Vergata, V.le Oxford, 81, 00133, Rome, Italy \\ ${ }^{2}$ Section of Medical and Surgical Lung Diseases, Department of Biomedicine and Prevention, Tor Vergata University, \\ Via Montpellier 1, 00133 Rome, Italy
}

Correspondence should be addressed to Eugenio Pompeo; pompeo@med.uniroma2.it

Received 21 November 2013; Accepted 2 January 2014; Published 9 March 2014

Academic Editors: M. Bonay, F. García-Río, K. Nishimura, and M. Nosotti

Copyright (C) 2014 Eugenio Pompeo. This is an open access article distributed under the Creative Commons Attribution License, which permits unrestricted use, distribution, and reproduction in any medium, provided the original work is properly cited.

\begin{abstract}
Lung volume reduction surgery (LVRS) has shown an improve for up to several years respiratory function, exercise capacity, and quality of life in selected patients with severe emphysema and low exercise capacity, particularly if upper-lobe predominance of disease is radiologically recognized. However, mortality and morbidity rates of LVRS have been not negligible leading to raising question as to the cost-effectiveness of the procedure and resulting in a progressive decline in its use although a considerable number of patients meet selection criteria and could potentially benefit of this treatment modality. In recent years, an active investigation aimed at developing less invasive strategies that might allow us to achieve long-term results as satisfactory as those of the standard LVRS method but with fewer adverse effects has been undertaken. So far, novel options including nonresectional surgical and endoscopic LVRS methods hold promise but results from large studies with long follow-up are awaited to help define the most effective interventional treatment options for patients with severe emphysema. In this literature review an analysis of the main issues related to LVRS including selection criteria, mechanisms of action, results of currently available surgical and endoscopic methods, and some potential future perspectives is provided.
\end{abstract}

\section{Introduction}

Emphysema, one of the recognized chronic obstructive pulmonary disease (COPD) phenotypes, is an incurable, highly prevalent, and underdiagnosed condition, which represents the 4 th cause of death in adults worldwide [1].

It is defined as an abnormal permanent enlargement of air spaces distal to the terminal bronchiole associated with destruction of their walls [2].

Pathophysiology of emphysema include reduced area for gas exchange and decreased lung elastic recoil with early expiratory airway collapse and increased airflow resistance resulting in lung hyperinflation. This effect is exaggerated during exercise when dynamic hyperinflation further impairs respiratory mechanics, increases work of breathing, and may even hinder cardiac filling, leading to dyspnea and reduced exercise performance. The cascade of detrimental effects of emphysema eventually impairs quality of life and increases mortality [3-6].

In the last 2 decades lung volume reduction surgery (LVRS) has emerged as an effective treatment modality, which can reverse detrimental effects of emphysema for a variable period of time leading to significant and long-lasting improvements in respiratory function, exercise capacity, quality of life, and survival [7-13].

Randomized studies [14-20] including the large multiinstitutional National Emphysema Treatment Trial (NETT) [21] have confirmed that LVRS can offer superior benefits than optimized medical therapy including respiratory rehabilitation, particularly in patients with upper-lobe predominant emphysema and low exercise capacity. However, provided the fragile clinical status of patients with advanced emphysema, mortality and morbidity rates of LVRS have been not negligible and in the NETT up to $28 \%$ of patients 
have been reported to need in-hospital stay or rehabilitation facilities for 1 month or more after surgery [22].

These figures have led to raising question about the costeffectiveness of LVRS [23] and have stimulated the development of potentially less morbid strategies of treatment.

Thus fur, quite many LVRS-related issues still merit further investigation and a number of novel surgical [12, 20] and bronchoscopic lung volume reduction (BLVR) methods are under active scrutiny [24-37].

In this review I sought to critically analyze the current state-of-the-art and potential future perspectives on this topic.

\section{Background}

LVRS was proposed in 1957 by Brantigan and Mueller [38] who performed bilateral nonanatomic resection of emphysematous lung tissue through staged thoracotomy. They believed that a reduction of $20-30 \%$ of the overall lung volume would have led to a more physiologic reconfiguration of the chest wall and diaphragm as well as restoring radial traction on the bronchi, thereby relieving expiratory flow obstruction [39].

By 1961, Brantigan et al. [40] had performed LVRS on 56 patients. Unfortunately although nearly $90 \%$ of the patients had improved in symptoms, LVRS was rapidly abandoned at that time because of an $18 \%$ mortality rate and the lack of objectively documented benefits.

About 4 decades later, Cooper et al. [7] revisited Brantigan's idea proposing some technical refinements to the original procedure including use of median sternotomy and simultaneous (one-stage) bilateral staple lung resection. In that study there was no operative mortality and comprehensive outcome assessment showed significant improvements in dyspnea, pulmonary function, exercise tolerance, quality of life measures, and rate of independency from supplemental oxygen. Thereafter, several other surgical teams produced similar satisfactory results and in an attempt to reduce the typical procedure-related morbidity reported with open approaches, LVRS started being performed also by videoassisted thoracic surgery (VATS) either unilaterally [41-43] or bilaterally [44-47].

\section{Selection Criteria}

LVRS can be considered in patients, with COPD who are severely symptomatic and fail to improve despite optimized medical treatment including pulmonary rehabilitation.

Patients in whom predominant emphysema is suspected to be following medical history, routine chest roentgenograms and spirometry, should undergo high-resolution computed tomography (CT), measurement of static lung volumes by body plethysmography, and assessment of diffusing capacity for carbon monoxide (DLCO).

A diagnosis of severe emphysema with disabling dyspnea, moderate-to-severe obstructive defect, high residual volume (RV), and limited exercise capacity are amongst standard inclusion criteria [48] (Table 1).
TABLE 1: Suggested main selection criteria for LVRS.

\begin{tabular}{ll}
\hline Inclusion criteria & Exclusion criteria \\
\hline Age $\leq 80$ years & $\mathrm{BMI}<18>29$ \\
\hline $\begin{array}{l}\text { Severe, heterogeneous } \\
\text { emphysema, preferably } \\
\text { predominant in the upper lobes } \\
\text { at the HRCT. }\end{array}$ & $\begin{array}{l}\text { Severe, homogeneous } \\
\text { emphysema with no target areas } \\
\text { for LVRS at the HRCT. }\end{array}$ \\
\hline
\end{tabular}

Dyspnea at rest or with minimal

physical activity Need of ventilatory assistance.

(MMRC score $\geq 3$ ).

Moderate to severe obstructive

defect with $\mathrm{FEV}_{1} \leq 45 \%$ but

DLCO $<20 \%$ predicted by the

$>20 \%$ predicted.

Functional aspects of

hyperinflation with residual

volume $>180 \%$ predicted and

total lung capacity $>120 \%$

predicted on body

plethysmography.

\begin{tabular}{ll}
\hline Resting room & Resting $\mathrm{PaCO}_{2}>55 \mathrm{mmHg}$ \\
$\mathrm{PaO}_{2}>45 \mathrm{mmHg}$ &
\end{tabular}

$\mathrm{PaO}_{2}>45 \mathrm{mmHg}$

Pulmonary hypertension with

Impaired exercise capacity but 6MWT distance $>140 \mathrm{~m}$.

mean PA pressure $>35 \mathrm{mmHg}$ or peak systolic PA pressure $>50 \mathrm{mmHg}$ on Doppler echocardiography.

Any comorbid condition that

ASA score $\leq 3$. would significantly increase operative risk.

Quit smoking for at least $4 \quad$ Neoplastic disease with life

months. $\quad$ expectancy $<12$ months.

HRCT: high-resolution computed tomography; LVRS: lung volume reduction surgery; MMRC: modified Medical Research Council dyspnea score; $\mathrm{FEV}_{1}$ : forced expiratory volume in one second; DLCO: diffusion capacity for carbon monoxide; $\mathrm{PaO}_{2}$ : arterial oxygen pressure; $\mathrm{PaCO}_{2}$ : arterial carbon dioxide pressure; $6 \mathrm{MWT}$ : 6-minute walking test; PA: pulmonary artery; ASA: American Society of Anesthesiology score.

Radiologically, candidates for LVRS should disclose signs of lung hyperinflation with flat diaphragms on chest X-rays and areas of severe emphysema intermingled with better preserved lung tissue (heterogeneous emphysema) on CT scan (Figure 1).

The NETT definitively confirmed previous studies' findings indicating that patients, with upper-lobe predominant emphysema and low exercise capacity represent the ideal candidates for LVRS in terms of expected magnitude and duration of benefits [21].

NETT also indicated that patients with forced expiratory volume in one second $\left(\mathrm{FEV}_{1}\right) \leq 20 \%$ predicted and either homogeneous emphysema or DLCO $\leq 20 \%$ predicted, had a mortality rate of $16 \%$ and should thus be considered noneligible for the operation [49].

An asymmetric distribution of emphysema with more severe destruction in a single lung has been considered as an elective indication for unilateral LVRS [11, 42].

Inspiratory resistance of the airways, though not commonly employed, has been proposed as a marker of the 


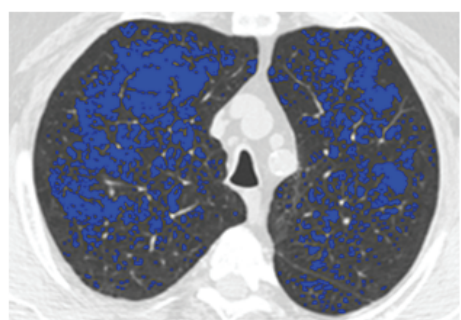

(a)

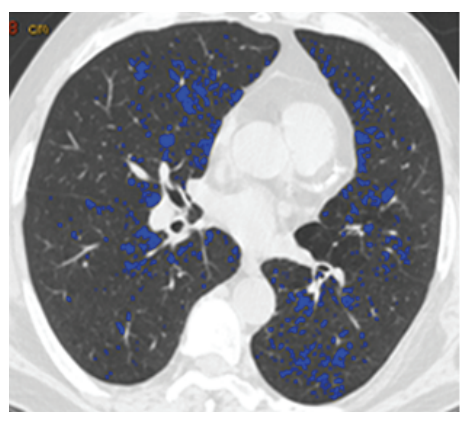

(b)

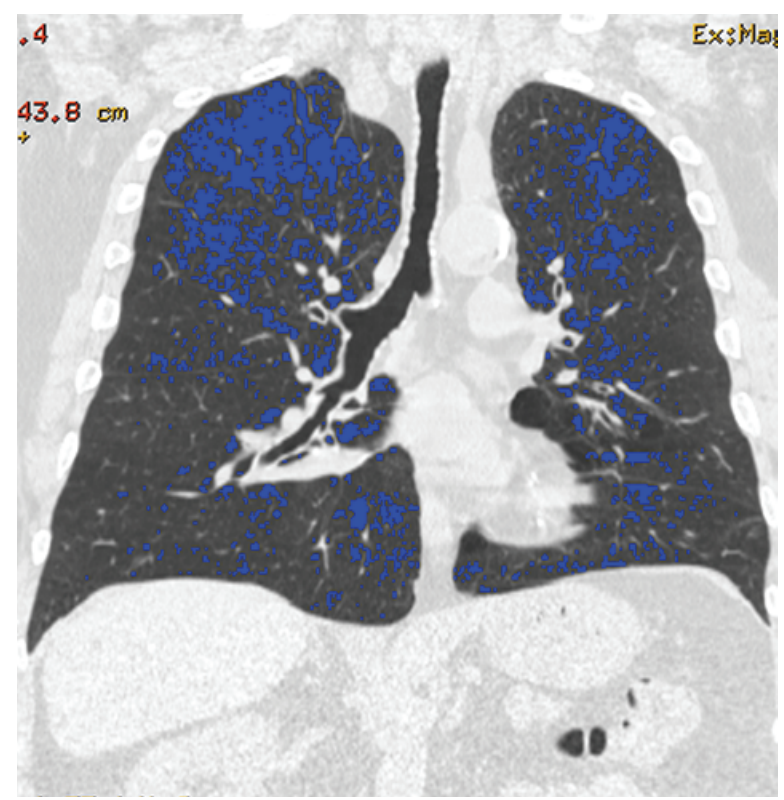

(c)

FIGURE 1: Axial ((a) and (b)) and coronal (c) TC imaging of an optimal candidate for LVRS due to severe upper-lobe predominant emphysema associated with relatively better preserved lower lobes lung tissue. Multiplanar reconstruction algorithm allows quantifying the extent of emphysema and provides coloured contrast enhancement (in blue) of the target regions for LVRS.

bronchitis component, with high values deemed to predict a poor response to LVRS [50]. However, Washko and coworkers [51] reported that static lun recoil pressure at total lung capacity (TLC), inspiratory resistance, and CT measures of the airway disease did not predict improvements in either FEV1 or maximal exercise.

Hypoxemia and need of supplemental oxygen are commonly found in LVRS candidates and usually do not contraindicate the procedure.

Stable abstinence from cigarette smoking is mandatory to minimize operative risks and confirm the patient's motivation to be enrolled in a surgical program.

If it does exist the suspicion of latent or occult ischemic cardiac disease, a careful investigation including pharmacologic stress test and, if necessary, coronary angiography, should be performed due to the high prevalence of coronary artery disease in patients with COPD [52].

Exclusion criteria include lack of adequate heterogeneity on CT imaging and too severely impaired respiratory function or exercise capacity, as well as comorbid conditions that are likely to predict a poor response to LVRS or to increase prohibitively the surgical risk (Table 1).

\section{Mechanisms of Improvement}

Surgical removal of hyperinflated and emphysematous lung tissue induces mechanical stretching of the remaining lung. An unchanged chest wall operating on a smaller lung is thought to partially restore the elastic recoil [53] whereas the expiratory flow at any given lung volume is thought to increase due to improved airway traction and delayed airway closure. Reduced thoracic gas compression and improved expiratory flow may translate into improvement in chest wall and diaphragm configuration/mechanics, reduced dynamic hyperinflation [54] and work of breathing, and better cardiac performance [55].

4.1. Lung Elastic Recoil. Sciurba and coworkers [56] first reported that lung elastic recoil can improve after LVRS and that the greater is the increase in elastic recoil, the greater the maximal improvements in exercise tolerance, and the larger the decrease in RV. In addition, Gelb and coworkers [57] have found a correlation between improvements in elastic recoil and decreased transmural pressure, improved airway conductance, and better expiratory airflow. However, Ingenito and coworkers [58] reported that improvement in expiratory flows after LVRS can be largely accounted for by increases in vital capacity without significant changes in the $\mathrm{FEV}_{1}$ to forced vital capacity (FVC) ratio. These findings support the theoretical model proposed by Fessler and Permutt [59], according to which, following LVRS, the increase in FVC is the result of a resizing of the lung to the chest wall, which in turn induces an increase in recoil pressure at any given lung volume, without producing changes in either small airway conductance, airway closing pressure, or compliance. On the other hand, Tschernko and coworkers [60] found that measures reflecting the efficiency of ventilatory mechanics including work of breathing, intrinsic positive end-expiratory pressure, and dynamic compliance, improved all after LVRS due to a relief of thoracic distention and reduced airway resistance. 
4.2. Chest Wall and Diaphragm Configuration. Lando and coworkers [61] reported that LVRS decreases middle-tolower anterior-to-posterior rib cage diameter as assessed by chest radiography and CT whereas, in another elegant study, Cassart et al. [62] have found that by decreasing the overall lung volume, LVRS makes the diaphragm dome move upwards and increases the area of muscle juxtaposed to the rib cage. Lower operating lung volumes have been reported to eventually lead to improvements in strength and efficiency of inspiratory muscles.

Bloch and coworkers [63], by employing respiratory inductive plethysmography, had shown that during quite breathing, LVRS did not increase tidal volume, respiratory cycle times, or minute ventilation but resulted in better synchronization of rib cage-abdominal motion due to greater contribution of abdominal volume changes to tidal volumes, which were deemed consistent with lower inspiratory loading and greater force-generating capacity of the diaphragm.

4.3. Gas Exchange. Beneficial effects of LVRS on gas exchange have been attributed to an improved regional ventilation or perfusion matching that follow the recruitment of previously compressed but functionally preserved lung regions [64] although results of LVRS on arterial oxygenation have been variable. Some investigators $[65,66]$ have found that LVRS can increase arterial oxygen tension $\mathrm{PaO}_{2}$ in a significant manner whereas Geddes et al. [15] reported trivial improvement of $\mathrm{PaO}_{2}$ and arterial carbon dioxide tension $\left(\mathrm{PaCO}_{2}\right)$ after surgery. However, a recent meta-analysis of randomized trials indicated that following LVRS, significant improvements occur both in $\mathrm{PaO}_{2}$ and $\mathrm{PaCO}_{2}$ [67]. In an analysis of the NETT cohort, Criner and coworkers [68] reported that following LVRS, patients with upper-lobe emphysema on maximal exercise showed higher output of $\mathrm{CO}_{2}$, greater tidal volume, and increased hearth rate, which were associated with slower and deeper breathing patterns lasting for up to 24 months.

4.4. Oxygen Consumption. Takayama and coworkers [69] reported a significant reduction in oxygen cost which proved inversely correlated with improvements in $\mathrm{FEV}_{1}(R=-0.70$, $P<0.001)$ and directly correlated with RV/TLC $(R=0.54$, $P<0.01)$. In addition LVRS reduced oxygen consumption of respiratory muscles at maximal ventilation from $55.5 \%$ to 49.0\% $(P<0.05)$.

Our group [70] reported that LVRS significantly decreased oxygen consumption volume and resting energy expenditure when compared to the effects of respiratory rehabilitation and that substrate oxidation changed from prevalent lipid to prevalent carbohydrate. The significant correlations we have found with RV and nutritional status suggested improvements in respiratory mechanics, energy expenditure and metabolism towards normal ranges.

4.5. Cardiocirculatory Function. Right and left ventricular function can be impaired in patients with advanced emphysema due to reduced end-diastolic volumes. On the other hand beneficial effects of LVRS on right ventricular filling and performance have been hypothesized by our group [71] who reported that improvements in right ventricular function indexes occurred on exercise after LVRS and correlated with a reduction in RV/TLC. In a similar manner, Jörgensen et al. [72] reported post-LVRS increases in left ventricular end-diastolic dimensions and filling, eventually resulting in improved left ventricular function.

In an analysis from the NETT on pulmonary hemodynamic changes at rest, Criner et al. [73] reported that except for a smaller change in end-expiratory capillary wedge pressure, compared with medical treatment, LVRS was not associated with an increase in pulmonary artery pressures. On the other hand, due to the typically irregular distribution of emphysema, removal of lung areas receiving substantive degrees of perfusion must be limited at most since a reduction in pulmonary vascular bed due to LVRS, anecdotally resulted in pulmonary hypertension [74].

\section{One-Stage Bilateral LVRS}

One-stage bilateral LVRS is the most widely adopted approach since it produced greater functional and clinical improvements than unilateral treatment $[43,75]$.

The standard technique entails nonanatomical staple resection of the most emphysematous lung tissue (resectional LVRS) carried out on both lungs by median sternotomy $[9,10]$ or VATS $[44,46]$ through general anesthesia and single-lung ventilation.

Results of bilateral LVRS proved comparable either by VATS or median sternotomy [76] although satisfactory results have been also achieved through bilateral staged thoracotomy [77] or the clamshell incision [78].

VATS has been deemed more difficult to be accomplished in presence of pleural adhesions although feasibility by this approach has been shown to be usually not compromised by pleural adhesions [79].

5.1. Mortality and Morbidity. The poor clinical status of patients undergoing LVRS has resulted in mortality and morbidity rates that have been not negligible. In fact, mortality rates ranged between 0 and $17 \%$ in previous studies (Table 2) whereas an overall morbidity rate of $59 \%$ has been reported in the NETT [22]. In this large study, major pulmonary and cardiovascular morbidity within 90 days post-LVRS occurred in $30 \%$ and $20 \%$ of patients, respectively. Cardiac arrhythmia was the most common complication with a rate of $23.5 \%$. Rates for pneumonia and need of reintubation were $18 \%$ and $22 \%$, respectively. Other reported causes of morbidity include bleeding, respiratory failure and gastrointestinal complications whereas late complications after LVRS include pulmonary hypertension [74], secondary pneumothorax [80], metallophtysis (i.e., asymptomatic expectoration of steel staples) [81], and the development of giant bullous emphysema [82].

In a further analysis from the NETT comparing median sternotomy versus VATS results [76], 90-day mortality was $5.9 \%$ for median sternotomy and $4.6 \%$ for VATS with no intergroup difference. Hospital stay was also comparable but 
TABLE 2: Perioperative results of randomized studies on LVRS.

\begin{tabular}{|c|c|c|c|c|c|c|c|c|}
\hline $\begin{array}{l}\text { First } \\
\text { author }\end{array}$ & Year & $\begin{array}{c}\text { Total/ } \\
\text { surgical } \\
\operatorname{arm}(N)\end{array}$ & $\begin{array}{l}\text { Surgical } \\
\text { approach }\end{array}$ & $\begin{array}{l}\text { LVRS } \\
\text { method }\end{array}$ & $\begin{array}{c}\text { LVRS } \\
\text { extension }\end{array}$ & $\begin{array}{c}\text { Operative } \\
\text { mortality } \\
(\%)\end{array}$ & $\begin{array}{l}\text { Morbidity } \\
(\%)\end{array}$ & $\begin{array}{c}\text { Hospital stay } \\
\text { (mean) }\end{array}$ \\
\hline Criner [14] & 1999 & $37 / 32$ & MS & Resectional & Bilateral & 9.4 & $15.6^{\mathrm{M}}$ & - \\
\hline Geddes [15] & 2000 & $48 / 23$ & MS/VATS & Resectional & Bilateral & 17 & $22^{\mathrm{A}}$ & 19 \\
\hline Pompeo [16] & 2000 & $60 / 30$ & VATS & Resectional & Unilateral/bilateral & 3.3 & $53^{\mathrm{A}}$ & 13.6 \\
\hline $\begin{array}{l}\text { Goldstein } \\
{[17]}\end{array}$ & 2003 & $55 / 28$ & VATS/MS & Resectional & Bilateral/unilateral & 7.1 & $14.2^{\mathrm{M}}$ & - \\
\hline $\begin{array}{l}\text { DeCamp Jr } \\
{[22]}\end{array}$ & 2008 & $1218 / 608$ & MS/VATS & Resectional & Bilateral & 5.2 & $58.7^{\mathrm{A}}$ & - \\
\hline Hillerdal [18] & 2005 & $105 / 49$ & MS/VATS & Resectional & Bilateral & 12 & - & - \\
\hline Miller [19] & 2006 & $93 / 54$ & MS/VATS & Resectional & Bilateral & 1.5 & - & $12-22$ \\
\hline \multirow{2}{*}{ Pompeo [20] } & \multirow{2}{*}{2012} & $63 / 31^{*}$ & VATS & Resectional & Unilateral & 3.2 & $48.3^{\mathrm{A}}$ & $7.5^{\circ}$ \\
\hline & & $63 / 32^{*}$ & AVATS & Nonresectional & Unilateral & 0 & $18.7^{\mathrm{A}}$ & $6^{\circ}$ \\
\hline
\end{tabular}

LVRS: lung volume reduction; MS: median sternotomy; MS: median sternotomy; VATS: video-assisted thoracic surgery; AVATS: awake VATS; ${ }^{*}$ both arms were surgical. ${ }^{\mathrm{A}}$ All events; ${ }^{\mathrm{M}}$ major morbidity; ${ }^{\circ}$ median value.

30 days after surgery patients who were living independently were $70.5 \%$ after median sternotomy compared to $81 \%$ after VATS $(P=0.02)$. In addition, overall costs related to LVRS were less for VATS compared to median sternotomy $(P=$ $0.03)$.

Naunheim and colleagues [83] analyzed risk factors for mortality and morbidity amongst NETT nonhigh risk patients. They have found that age, $\mathrm{FEV}_{1}$, and DLCO were risk factors for major pulmonary morbidity whereas non-upper-lobe predominant distribution of emphysema increased operative mortality and cardiovascular morbidity with odds ratios of 2.99 and 2.67, respectively. Conversely, in contrast to previous literature, NETT data did not indicate hypercapnia or poor exercise tolerance as predictors of worse outcome although a potential bias in the NETT was the intentional exclusion of patients with a $\mathrm{PaCO}_{2}>60 \mathrm{mmHg}$ $(55 \mathrm{mmHg}$ in one Center) and of those walking $140 \mathrm{~m}$ or less on 6-minute walking test (6MWT) [52].

Air leaks represent the most frequent minor adverse event after LVRS occurring in up to $90 \%$ of patients postoperatively and lasting more than 30 days in about $12 \%$ of instances [84].

To limit the occurrence of air leaks, use of exogenous buttressing material along the suture lines of lung tissue resection was recommended [85-89].

Cooper and coworkers [85] reported prolonged air leaks in $46 \%$ out of 150 patients undergoing bilateral LVRS with bovine pericardium buttress and pleural tenting used as adjunctive sealant methods.

Hazelrigg et al. [90] reported on a slight reduction of air leaks duration and hospital stay with buttressed LVRS with no cost advantage. Moreover, in a three-centre randomized study comparing bovine pericardium buttress versus no buttress [91], a significant reduction in air leaks was found in the buttressed group whereas no difference was detected in hospital stay amongst study groups.

DeCamp et al. [84], in a post hoc analysis of the NETT, have found no advantage in air leaks duration with the use of various buttressing material including bovine pericardium, polytetrafluoroethylene, or fibrin glue. Air leaks duration was longer in caucasians and in association with lower $\mathrm{FEV}_{1}$ or DLCO, use of inhaled steroids, upper-lobe predominant emphysema, and presence of pleural adhesions. Postoperative complications were greater in patients with air leaks $(57 \%$ versus $30 \%, P=0.0004$ ) and postoperative stay was longer (11.8 \pm 6.5 days versus $7.6 \pm 4.4$ days, $P=0.0005)$.

Finally, in a more recent comparative analysis of resectional versus nonresectional LVRS, we have found that at univariate analysis, resectional LVRS, higher severity of emphysema and lower DLCO correlated significantly with occurrence of prolonged air leaks, whereas at multivariate analysis, higher severity of emphysema was the only factor predicting prolonged air leaks (odds ratio $=4.85, P<0.0001$ ) [92].

5.2. Clinical Outcome. Reported benefits of LVRS include significant improvements in respiratory function, exercise capacity [7-14], subjective dyspnea [93], quality of life measures [94-96], and survival [99]. Other less frequently reported benefits include improvements in oxygenation [64$67]$, body weight, and nutritional status [97, 98], cardiac function [71, 72], cognitive function [100], alveolar ventilation [101], and breathing pattern $[63,68]$.

In particular, Ciccone et al. [9] reported that $\mathrm{FEV}_{1}$ improved at 6 months by up to $56 \%$ whereas RV, $6 \mathrm{MWT}$, and short-form-36 physical functioning quality of life domain (SF-36 PF) improved acutely by $33 \%, 25 \%$, and $67 \%$, respectively, and remained significantly improved for up to 5 years. In addition, in a series from Gelb et al. [8], $\mathrm{FEV}_{1}$ improved by more than $200 \mathrm{~mL}$ and/or FVC by more than $400 \mathrm{~mL}$ for up to 4 and 5 years, in $27 \%$ and $8 \%$, of 26 patients with complete follow-up data, respectively. Overall, superior and longer lasting benefits have been reported in patients with upper-lobe predominant emphysema $[9,21,48]$. However, Weder and coworkers [13] reported satisfactory improvements for up to 36 months even in patients with homogeneous emphysema who also showed a 5-year survival 
comparing that of patients with heterogeneous disease $(64 \%$ versus $73 \%$ ).

In the NETT [21], 1218 patients were randomized to receive either LVRS or medical therapy. Maximal exercise capacity improved $\geq 10 \mathrm{~W}$ in $28 \%, 22 \%$, and $15 \%$ of $608 \mathrm{LVRS}$ patients after 6,12 , and 24 months, respectively, compared to $4 \%, 5 \%$, and $3 \%$ of control group patients. Additionally, patients who underwent LVRS were more likely to achieve improvements in 6MWT, $\mathrm{FEV}_{1}$, severity of dyspnea, and quality of life measures compared to the control group.

One important feature of the NETT was that overall results were analyzed also according to some baseline characteristics including the craniocaudal distribution of emphysema on chest CT and results of postrehabilitation maximum exercise capacity. The combinations of high and low exercise capacity with upper-lobe or non-upper lobe predominance of emphysema at the chest CT led to division of patients into 4 subgroups.

At a mean follow-up of 2.4 years, in 290 patients with upper-lobe predominant emphysema and low exercise capacity, LVRS resulted in a lower risk of death than medical therapy ( $R R$ 0.47, $P=0.005$ ). Also, this subgroup more likely achieved a meaningful improvement in maximum exercise $(\geq 10 \mathrm{~W})$ at 24 months $(30 \%$ versus $0 \% ; P<0.001)$ and an improvement in quality of life defined by a reduction of the St. George's Respiratory Questionnaire (SGRQ) $\geq 10$ points (48\% versus $10 \%$; $P<0.001$ ).

Amongst 419 patients with upper-lobe predominant emphysema and high exercise capacity, LVRS had no impact on survival but was more likely to induce an improvement in maximum exercise testing at 24 months (15\% versus $3 \%, P=$ 0.001 and SGRQ (41\% versus $11 \%, P<0.001$ ) as compared to medical therapy.

In 149 patients with non-upper-lobe predominant disease and low exercise capacity, LVRS had no impact on survival or maximum exercise capacity. However, surgery was more likely to improve SGRQ at 24 months (37\% versus 7\%, $P=$ 0.001).

Finally amongst 220 patients with non-upper-lobe predominant emphysema and high exercise at baseline, LVRS increased the risk for death ( RR 2.06, $P=0.02$ ) and had no effect on maximum exercise capacity or quality of life at 24 months.

Recently, Lammi and coworkers [102], in a 59-patients series of patients undergoing LVRS with the same selection criteria employed in the NETT, reported a higher rate of responders in $6 \mathrm{MWT}$ (increase $>54 \mathrm{~m}$ ) at $6(46 \%$ versus $28 \%$ ) and 12 months (51\% versus 28\%) and in $\mathrm{FEV}_{1}$ (increase $>12 \%$ or $200 \mathrm{~mL}$ ) for up to 36 months (57\% versus $29 \%$ ).

As far as less commonly reported beneficial effects of LVRS are concerned; Washko and coworkers [103] have shown in an ancillary NETT study that surgery reduced by about $30 \%$ the rate of COPD exacerbation, an effect which did not occur in the medical arm and which correlated with the degree of improvement in $\mathrm{FEV}_{1}$. In another ancillary NETT analysis, Kozora and coworkers [100] reported that 6 months after LVRS patients improved in psychomotor speed, verbal memory, and naming skills. In addition, surgical patients had a greater decline in depressive symptoms compared with patients in the medical arm. Finally, Armstrong et al. [104] investigated response to LVRS versus medical therapy of chronotropic incompetence, which is a marker of poor prognosis in patients with COPD. They found that 6 months after LVRS, mean percent of predicted heart rate reserve improved from $41 \%$ to $50 \%(P<0.001)$ whereas no change occurred in the control group.

A longer-term follow-up analysis of the NETT [10] with a median follow-up of 4.3 years has shown that despite an expected higher postoperative mortality, LVRS offered a survival advantage compared to medical treatment (total mortality, 0.11 deaths per person-year with LVRS and 0.13 with medical therapy, $P=0.02$ ).

At follow-up of 1,2 , and 3 years, exercise capacity improved $10 \mathrm{~W}$ or more in $23 \%, 15 \%$, and $9 \%$ of LVRS patients, respectively, compared with $5 \%, 3 \%$, and $1 \%$ of the medical patients $(P<0.001$ at each time point). In addition, after LVRS, SGRQ score improved (decreased) by 8 units or more in $40 \%, 32 \%, 20 \%, 10 \%$, and $13 \%$ compared to $9 \%$, $8 \%, 8 \%, 4 \%$, and $7 \%$ following medical care at $1-5$ years of follow-up (years 1-3, $P<0.001$; year $4, P=0.005$; year $5, P=0.12$ ). Furthermore, in 290 patients with upperlobe predominant emphysema and low exercise capacity, LVRS provided a substantial survival advantage compared to medical treatment and also greater improvements in exercise capacity and quality of life.

In a further analysis, Chandra et al. [105] suggested a complimentary role of lung perfusion scintigraphy with highresolution CT and identified as optimal responders to LVRS patients with both upper-lobe predominant emphysema at CT scan and low upper-lobe perfusion $(<20 \%$ of the total) at perfusion scintigraphy.

\section{Unilateral LVRS}

Theoretically, unilateral LVRS could offer the advantage to be a less morbid surgical approach than one-stage bilateral treatment, particularly if VATS is the preferred approach $[76,106,107]$. Unfortunately so far, no randomized study has compared results of unilateral versus bilateral LVRS and the former has been mainly employed as a second choice option in patients with previous thoracic surgery or pleurodesis on one, side and in those who were deemed unfit for a bilateral procedure due to advanced age or associated comorbidities [108].

As expectable, bilateral LVRS produced greater improvement in $\mathrm{FEV}_{1}$, dyspnea, and exercise capacity than unilateral procedures [109]. However, Brenner et al. [107] have reported that $\mathrm{FEV}_{1}$ improved $39 \%$ following a bilateral and $25 \%$ after unilateral LVRS, a finding which suggests the potential of unilateral LVRS to affect the function in the nonoperated lung due to lungs-compliance-related interdependence [110]. Moreover, in the study from Brenner et al. [107] $\mathrm{FEV}_{1}$ decay averaged $255 \mathrm{~mL} /$ year after bilateral LVRS and $107 \mathrm{~mL} /$ year after unilateral procedures, leading to hypothesize that simultaneous bilateral treatment induces a greater mechanical stress in the lungs, which may translate in a steeper functional decay than after unilateral LVRS. 
TABLE 3: Operative results of unilateral LVRS.

\begin{tabular}{|c|c|c|c|c|c|c|}
\hline First author & Year & Surgical approach & Patients $(N)$ & Mortality (\%) & Hospital stay & $\mathrm{FEV}_{1}$ increase (\%) \\
\hline Keenan [41] & 1996 & VATS & 67 & 5.9 & 17 & 27 \\
\hline McKenna Jr [109] & 1996 & VATS & 87 & 3.5 & 11.4 & 31 \\
\hline Keller [93] & 1997 & VATS & 25 & 0 & 8.8 & 31 \\
\hline Argenziano [78] & 1997 & MS/VATS & 28 & 3.6 & - & 28 \\
\hline Kotloff [43] & 1998 & MS/VATS & 32 & 0 & 14.2 & 24 \\
\hline Geiser [152] & 2001 & VATS & 28 & 0 & - & 18 \\
\hline Mineo [11] & 2005 & VATS & 97 & 1.03 & $9^{*}$ & 36 \\
\hline Meyers [153] & 2008 & $\mathrm{~T} / \mathrm{MS}$ & 43 & 2.3 & $8^{*}$ & 25 \\
\hline
\end{tabular}

$\mathrm{FEV}_{1}$ : forced expiratory volume in one second; MS: median sternotomy; VATS: video-assisted thoracic surgery; T: thoracotomy; ${ }^{*}$ median value.

In other reported series, unilateral LVRS resulted in mortality rates of $0-2.3 \%$, a hospital stay of $8-17$ days, and a $\%$ increase of $\mathrm{FEV}_{1}$ of $18-31 \%$ (Table 3 ).

Surgically oriented visual grading systems [111] and quantitative CT analysis [110] have been developed to help identify optimal candidates for unilateral treatment. In fact, by applying a visual grading system we have found that $\mathrm{FEV}_{1}$ improved up to $500 \mathrm{~mL}$ in patients with heterogeneous but symmetric emphysema undergoing one-stage bilateral LVRS, and $440 \mathrm{~mL}$ in patients with asymmetric emphysema undergoing unilateral treatment [111].

In a multi-institutional comparative study, Lowdermilk and colleagues [112] reported that $\mathrm{FEV}_{1}, \mathrm{FVC}, \mathrm{RV}$, quality of life, and dyspnea improved significantly more after bilateral than after unilateral LVRS whereas no intergroup difference was found in arterial oxygenation, 6MWT, and decrease in oxygen utilization.

In a series of 97 patiens undergoing intentional unilateral LVRS by VATS, we reported that following significant peak improvements at 6 months, $\mathrm{FEV}_{1}, \mathrm{RV}, 6 \mathrm{MWT}$, and SF-36 PF domain score were still improved by $24 \%, 18 \%$ and $100 \%$ at 3 years. In addition, RV, 6MWT, and SF-36 PF remained significantly better than baseline values for up to 5 years [11].

In a retrospective study, Serna and coworkers [113] reported 2-year survival of $86 \%$ and $73 \%$ after bilateral or unilateral LVRS, respectively. In addition, in a multi-institutional study [114] 3-year survival was $69 \%$ after unilateral and $74 \%$ after bilateral LVRS with no intergroup difference.

\section{Staged Bilateral LVRS}

The steeper postoperative decay in $\mathrm{FEV}_{1}$ observed with bilateral LVRS [107] and the possibility that unilateral treatment could positively affect the function of both lungs support a role for staged treatment. Nonetheless, data regarding the results of staged bilateral LVRS is scarce and so far no randomized comparisons with one-stage bilateral treatment do exist.

Kotloff et al. [43] reported that following staged bilateral LVRS, the contribution of each procedure to the peak improvement in $\mathrm{FEV}_{1}$ was $0.14 \mathrm{~L}$ after the first procedure and 0.13 after the second. Hazelrigg et al. [47] analyzed the results of one-stage versus staged bilateral LVRS. In the staged group by adopting a standardized 3 to 4 months interval between the procedures, complication rate and early outcomes were comparable but the sum of 2 hospitalizations times was longer than that in the one-stage group. Conversely, our group [115] reported on a comparative analysis of staged versus onestage bilateral LVRS in which the completion of the bilateral treatment was performed at the reappearance of severe disability. The mean interval between staged procedures was 15.2 months and although peak improvements were greater in the one-stage group, improvements in $\mathrm{FEV}_{1}, \mathrm{FVC}, \mathrm{RV}$, and 6MWT distance were more stable in the staged group. In addition at 36 months, RV was significantly lower in the staged group ( $4.6 \mathrm{~L}$ versus $5.3 \mathrm{~L}, P=0.01$ ).

In a further report we have shown that amongst 97 patients undergoing intentional unilateral LVRS, 70\% were still free from contralateral treatment at 5 years. Such a finding suggests that in selected patients postponement or even definitive avoidance of the contralateral treatment can be achieved by a staged strategy of treatment [11].

In accordance with our findings, Oey and coworkers [106] analyzed results of a 114-patients cohort undergoing onestage bilateral (26 patients) or unilateral (88 patients) LVRS that included the possibility of a staged bilateral procedure performed on patients request. At a median follow-up of 2.8 years, a staged bilateral treatment was performed in 16 patients with a median interval between the procedures of 3.9 years. There was no difference between the 3 groups in operative mortality and 5-year survival. However, results in the domain of physical functioning, social functioning, and energy/vitality were still significantly improved at 4 and 6 years, respectively, in the staged group only.

\section{LVRS and Lung Transplantation}

Lung transplantation and LVRS have both demonstrated to improve dyspnea, respiratory function, exercise capacity, and quality of life in patients with severe emphysema. However, due to a partial overlapping of selection criteria, identification of the appropriate candidate for each option is mandatory [116].

The age limit for lung transplantation is commonly 60 65 years. For older patients, LVRS remains the only surgical option to achieve a significant clinical benefit whereas patients aged 55-60 are more difficult to address since the 
benefits of LVRS may be lost over time when they reach an age limit which may be critical for lung transplantation.

In young patients who fulfill the criteria for both surgical treatments, LVRS can be performed first to postpone lung transplantation and thus avoid the negative side effects of chronic immunosuppression and medication. This is especially the case when heterogeneous distribution of emphysema is recognized on CT and perfusion scans because LVRS proved to be able to delay the need for lung transplantation by $3-6$ years $[117,118]$. Conversely, findings of homogeneous or $\alpha$-1-antitrypsin-deficiency-related emphysema, a $\mathrm{FEV}_{1}<$ $20 \%$ predicted, a DLCO $<20 \%$ predicted, and an elevated pulmonary artery pressure as well as the presence of scarring of the lungs or chronic inflammatory changes are also preferably addressed to lung transplantation $[49,116,119]$.

LVRS and lung transplantation may be complimentarily combined in several ways.

LVRS has been employed as a bridge to transplantation $[120,121]$ simultaneously with single lung transplantation to prevent native lung hyperexpansion [122] and early or late posttransplant to treat native lung hyperexpansion $[123,124]$.

As a rule, lung transplantation can be performed safely after LVRS with no adjunctive adverse effects although a higher number of blood transfusions may be required due to adhesions being developed after initial LVRS [117, 122], particularly if buttressed stapling devices have been employed. Nathan et al. [125], in a comparative analysis including 50 patients undergoing LVRS followed by lung transplant, and 741 patients undergoing sole lung-transplant, reported no intergroup difference in the need for reoperation, hospital stay, or survival. More recently, Shigemura et al. [126] reported that out of 177 lung transplant patients, a higher incidence of postoperative bleeding requiring reexploration and of renal dysfunction requiring dialysis occurred in 25 patients who underwent LVRS before lung transplantation. In addition in this series, peak $\mathrm{FEV}_{1}$ improvement was worse in patients with LVRS before lung transplantation ( $56.7 \%$ versus $78.8 \% ; P<0.05)$ whereas 5 -year survival was similar between the groups $(59.7 \%$ versus $66.2 \%)$.

\section{Nonresectional LVRS}

Historical background of nonresectional LVRS includes the technique developed by Crosa-Dorado et al. [127] in 1992, who proposed multiple fold plication of the most emphysematous regions performed by thoracotomy under general anesthesia. The technique was subsequently adapted by Swanson et al. [128] for a more reliable VATS application. A slightly different fold plication method was proposed subsequently by Iwasaki and coworkers [129].

In 2006, our group [130] reported feasibility and early results of a novel nonresectional LVRS technique, which entails an introflexive plication of the most emphysematous lung regions and was developed to be ideally performed in spontaneously ventilating awake patients through thoracic epidural anesthesia. This original method respects the basic concepts of resectional LVRS including a reduction of about $30 \%$ of the overall lung volume, suturing performed along a single ideal line and use of stapling devices. Yet, it adds some potential advantages including peripheral suturing, a linear but interrupted suture line which is more flexible, avoidance of any pleural discontinuation, and a 4-fold inlay buttress created by the plicated bullous tissue itself, which are aimed at facilitating postoperative lung reexpansion and at reducing the occurrence of air leaks.

Subsequently, in a 42-patients series we reported no 90-day mortality with significant 2-year improvements in $6 \mathrm{MWT} \mathrm{FEV}_{1}, \mathrm{FVC}$, and RV, and in the multidimensional body mass index, airflow obstruction, dyspnea, and exercise capacity index (BODE) [12].

More recently, our group [20] published results of a randomized study entailing 63 patients receiving awake nonresectional LVRS (32 patients) or standard resectional LVRS through general anesthesia (31 patients). In this study the proportion of patients who could be discharged within 6 days was significantly greater in the awake group (21 versus 10 patients, $P=0.01$ ). Nonfatal adverse events including air leaks were significantly less in the awake group (7 versus 16 , $P=0.01)$. At 6 months, $\mathrm{FEV}_{1}$ improved significantly in both study groups $(0.28 \mathrm{~L}$ versus $0.29 \mathrm{~L}, P=0.81)$ as did FVC, RV, 6MWT, and SF-36 PF score, which remained significantly better than baseline values for up to 24 months. At 36 months, freedom from contralateral treatment (55\% versus 50\%, $P=$ 0.7 ) and survival ( $81 \%$ versus $87 \%, P=0.5$ ) were comparable. A comparison of clinical results between nonresectional and resectional LVRS is depicted in Table 4.

\section{Redo LVRS}

A poorly investigated issue regards LVRS performed a second time on the same thoracic cavity (redo LVRS). It may be indicated in strictly selected patients who already underwent successful bilateral LVRS but have lost the initial benefit and have developed further lung target areas amenable to be excised or plicated surgically.

Stammberger et al. [131] first reported on a patient with alpha-1-antitrypsin deficiency emphysema who underwent redo LVRS with satisfactory outcome.

More recently our group [132] analyzed the results of a 17 patients series on redo LVRS. In this series, the surgical procedures entailed completion lobectomy in 7 patients and nonanatomic lung resection under general anesthesia or awake lung plication under epidural anesthesia in 5 patients each. Operative mortality was $11.7 \%$ (2 patients). The mean hospital stay was 9 days. Significant improvements occurred for up to 12 months in $\mathrm{FEV}_{1}(P<0.001)$, FVC $(P<0.002)$, RV $(P<0.001)$, 6MWT $(P<0.001)$, and dyspnea index $(P<0.001)$. In particular, at 6 months, improvements in $\mathrm{FEV}_{1}$ were greater than $200 \mathrm{~mL}$ in 11 patients and correlated with the postoperative reduction in $\mathrm{RV}(R=0.62, P=0.01)$.

\section{Bronchoscopic Lung Volume Reduction}

The typical LVRS-related morbidity has contributed to stimulate the development of investigational bronchoscopic lung volume reduction (BLVR) methods, which are currently 
TABLE 4: Results of randomized studies on LVRS*.

\begin{tabular}{|c|c|c|c|c|c|c|c|c|}
\hline First author & Year & Time of assessment (months) & $\mathrm{FEV}_{1}$ & RV & 6MWT & $\mathrm{PaO}_{2}$ & DLCO & Quality of life \\
\hline Criner [14] & 1999 & 3 & 31 & -24.5 & 9.4 & - & 16.6 & - \\
\hline Geddes [15] & 2000 & 6 & 23 & -28 & 29 & -4.1 & - & 41 (SF-36) \\
\hline Pompeo [16] & 2000 & 6 & 53 & -25 & 24 & 7 & - & - \\
\hline Goldstein [17] & 2003 & 6 & 37.5 & -16 & 4.1 & - & - & - \\
\hline Hillerdal [18] & 2005 & 6 & 24 & -25 & 35 & 5.2 & - & $\begin{array}{c}32 \text { (SGRQ) } \\
111(\mathrm{SF}-36, \mathrm{PF})\end{array}$ \\
\hline Miller [19] & 2006 & 6 & 27.5 & -25 & 13 & - & 15 & - \\
\hline \multirow[t]{2}{*}{ Pompeo [20] } & \multirow[t]{2}{*}{2012} & \multirow[t]{2}{*}{6} & 36 & -17.4 & 27 & 4.4 & - & 75.8 (SF-36, PF) \\
\hline & & & $35^{\S}$ & $-20.8^{\S}$ & $31^{\S}$ & $5.8^{\S}$ & - & $110(\mathrm{SF}-36, \mathrm{PF})^{\S}$ \\
\hline
\end{tabular}

${ }^{*}$ Surgical arms results of studies in which \% change from baseline values was computable are included. LVRS: lung volume reduction surgery; $\mathrm{FEV}_{1}$ : forced expiratory volume in one second; RV: residual volume; 6MWT: 6-minute walking test; $\mathrm{PaO}_{2}$ : arterial oxygen pressure; DLCO: diffusion capacity for carbon monoxide; SF-36: short form 36-items questionnaire; SGRQ: St.George questionnaire; PF: physical functioning domain score. ${ }^{\S}$ Results of awake nonresectional LVRS.

actively investigated. The main approaches can be divided into use of bronchial blocking devices, of devices working at the lung tissue level, and creation of extra-anatomical airways [133].

\subsection{Bronchial Blocking Devices}

11.1.1. Plugs. These devices are aimed at occluding the target bronchus leading to atelectasis and lung volume reduction.

So far, the only available plugs are the "Watanabe spigots" which are made of silicon and have a truncated conical shape with lateral studs to facilitate bronchial anchorage [134]. Watanabe spigots were initially introduced to treat pulmonary fistula and persistent pneumothorax with prolonged air leakage but have also been used to achieve BLVR in emphysema.

Results are limited to a small clinical series in which some clinical improvements and a $12.5 \%$ rate of pneumonias did occur [135]. A multicenter study using Watanabe spigots to treat emphysema is ongoing in Japan.

11.1.2. Endobronchial Valves. One-way endobronchial valves implanted into the airway are the most widely studied devices for BLVR. Their mechanism of action is promoting atelectasis of the target lung region/lobe by blocking regional inspiration but permitting expiration and drainage of secretions.

Currently, two types of valves have been more widely investigated: Zephyr valves (Pulmonx, Inc., Palo Alto, CA, USA) and IBV valves (Spiration Inc., Redmond, WA, USA). Both devices are self-expanding and are deployed under general anesthesia or sedation into segmental or subsegmental bronchi through a flexible or rigid bronchoscope using a catheter or guide wire.

Zephyr valves are made of a nitinol mesh covered by silicon, with a double silicon membrane inside that opens during expiration and closes during inspiration, a mechanism similar to Heimlich valves used for pleural drainage. Anchorage of the valve to the targeted bronchus is achieved via the irregular surface and self-expanding strength of the nitinol mesh.
The IBV valve is umbrella shaped and is made by a nitinol mesh covered by a polyurethane membrane. The valve is secured to the bronchial wall by hook-like anchors and can be removed by grasping and pulling on its proximal central rod with forceps. Both models are available in different sizes [133].

Following the first pilot studies $[25,29]$ on small number of patients documenting the safety and the feasibility of the procedures, few multicenter trials $[32,136,137]$ have been performed with either device showing some beneficial effects lasting for up to 12 months in selected patients (Table 5).

Main complications related to use of valves entailed pneumonia in $3.6-4.2 \%$ of patients, pneumothorax in $4.2-$ $4.5 \%$, hemoptysis in $5.4-6.1 \%$, and exacerbation of COPD in $7.9 \%$.

So far there is no comparative study demonstrating the advantages of one model of valve over another. One potential advantage of valves is their easy removability after implantation.

The best clinical and functional results have been correlated with the development of lobar atelectasis. Unfortunately, atelectasis occurs in a minority of patients [133] probably due to the presence of collateral ventilation. In fact, collateral ventilation, which may be present physiologically but can be greatly increased in severely emphysematous lungs [138, 139], allows air to enter the treated lobe through communications present at the level of the interlobar fissure, potentially jeopardizing the efficacy of the valves.

The evaluation of collateral ventilation is thus a crucial step in selecting patients that might benefit from valve BLVR and integrity of the interlobar fissure evaluated by CT scan has been deemed a good predictor of the absence of collateral ventilation [140]. In addition, quantitative instrumental estimation of collateral ventilation can be now performed with the use of an endobronchial catheter system (Chartis System, Pulmonx Inc., Redwood, CA, USA) that can be inserted through a flexible bronchoscope [141].

In a study performed on 20 patients, the resistance measurements assessed by this device correlated with postimplantation atelectasis in $90 \%$ of cases [142]. Small pilot 
TABLE 5: Results of bronchoscopic lung volume reduction.

\begin{tabular}{|c|c|c|c|c|c|c|c|c|}
\hline $\begin{array}{l}\text { Technique } \\
\text { and first } \\
\text { author }\end{array}$ & $\begin{array}{l}\text { Treated } \\
\text { patients } \\
(N)\end{array}$ & $\begin{array}{l}\text { Mortality } \\
(\%)\end{array}$ & $\begin{array}{l}\text { Maximal } \\
\text { follow-up } \\
\text { (months) }\end{array}$ & $\begin{array}{c}\mathrm{FEV}_{1} \\
\text { (\%increase) }\end{array}$ & $\begin{array}{c}\text { FVC } \\
\text { (\%increase) }\end{array}$ & $\begin{array}{c}\text { RV } \\
\text { (\%decrease) }\end{array}$ & $\begin{array}{c}6 \mathrm{MWT} \\
\text { (\%increase) }\end{array}$ & $\begin{array}{c}\text { Quality of life } \\
\text { (SGRQ score } \\
\text { decrease) }\end{array}$ \\
\hline \multicolumn{9}{|l|}{ Valves (Zephyr) } \\
\hline Sciurba [32] & 220 & 0.9 & 6 & 4.3 & NA & NA & 2.5 & 2.8 \\
\hline Herth [136] & 111 & 0.9 & 12 & 6 & NA & NA & NB & NB \\
\hline \multicolumn{9}{|l|}{ Valves (IBV) } \\
\hline Sterman [137] & 91 & 2.2 & 12 & NB & NB & NB & 5.9 & 8.7 \\
\hline \multicolumn{9}{|l|}{ Sealants } \\
\hline Criner [33] & $50\left(28^{\mathrm{L}}-22^{\mathrm{H}}\right)$ & - & 6 & $6.7-15.6$ & $5.1-9.1$ & $7.1-9.0$ & $7-3.4$ & $6.9-9-7$ \\
\hline Herth [144] & 21 & - & 6 & 11.4 & 15.5 & NB & NB & 7.5 \\
\hline \multicolumn{9}{|l|}{ Coils } \\
\hline Slebos [145] & 12 & - & 6 & 14.9 & 13.4 & 11.4 & 32.9 & 14.9 \\
\hline \multicolumn{9}{|l|}{ Vapor } \\
\hline Snell [36] & 11 & & 6 & NB & NB & NB & NB & 15.3 \\
\hline Snell [146] & 44 & 2 & 6 & 17 & 11 & 6 & 3 & 14 \\
\hline \multicolumn{9}{|l|}{ Airway Bypass } \\
\hline Shah [149] & 208 & 0.5 & 12 & NB & NB & NB & NB & NB \\
\hline
\end{tabular}

COPD: chronic obstructive pulmonary disease; $\mathrm{FEV}_{1}$ : forced expiratory volume in one second; VC: vital capacity; RV: residual volume; 6MWT: 6-minute walking test; SGRQ: St.George questionnaire; NA: not assessed; NB: no benefit; ${ }^{\mathrm{L}}$ low dose; ${ }^{\mathrm{H}}$ high dose.

studies using this catheter system are currently ongoing to optimize the selection of patients for BLVR.

\subsection{Devices Working at Lung Tissue Level}

11.2.1. Sealants. First-generation sealants employed in BLVR were biological substances aimed at obtaining atelectasis and subsequent fibrosis of lung regions, thus realizing a so-called biological lung volume reduction. Early experimental and clinical pilot studies [28, 143] demonstrated the safety and the efficacy of the technique. Thereafter, a large multicenter phase-2 dose-ranging trial was conducted in 50 patients with heterogeneous upper-lobe predominant emphysema [33]. The treatment consisted of bronchoscopic instillation of fibrinogen and thrombin solution that polymerized in situ to form a hydrogel able to initiate a localized inflammatory reaction that collapsed the lung region over 4-6 weeks. Overall 26 patients underwent a single treatment session whereas 24,2 sessions separated by 6-12 weeks.

At 12 weeks, in both groups there was a reduction in the $\mathrm{RV} / \mathrm{TLC}$ and improvements in $\mathrm{FEV}_{1}, \mathrm{FVC}$, and 6MWT. However, 6 months after treatment, all the functional outcome measures remained significantly improved in the high-dose group only.

First-generation biological substances have now been replaced by a synthetic polymeric foam (Aeris Therapeutics, Woburn, MA, USA), which is injected into the peripheral airways and acts as a glue that seals the subsegmental target regions eventually leading to airway collapse and atelectasis.

In a multicenter study on 25 patients with severe heterogeneous emphysema, Herth et al. [144] instilled synthetic polymer sealant in a staged fashion within a 12 -weeks period. After 24 weeks only the improvement in FVC was statistically significant. However, the results achieved in 14 COPD-stageIII patients were significantly better than those achieved in 11-stage IV patients in terms of improvement in FEV1 $(16 \%$ versus $2 \%$ ), FVC (24\% versus $3 \%$ ), RV/TLC (-7\% versus $-0.5 \%)$ and $6 \mathrm{MWT}$ ( $29 \mathrm{~m}$ versus $28 \mathrm{~m}$ ).

There were no serious periprocedural complications or treatment-related deaths in this series. Minor adverse events included a "flu-like" reaction with elevated inflammatory markers, dyspnea, fever, and leukocytosis that were generally self-limited and resolved within 24-96 h. COPD exacerbations occurred after treatment in 10 patients.

Potential advantages of sealants over endobronchial valves include the easy feasibility and the alveolar rather than bronchial level of action, which should thus not be influenced by collateral ventilation. On the other hand, in contrast to endobronchial valves, use of sealants is not reversible and optimal patient and target site selection are therefore crucial. The procedure is deemed not indicated in presence of bullae greater than $15 \mathrm{~cm}$ in maximal size as well as in patients with lower-lobe predominant emphysema whereas applicability of this method in patients with homogeneous emphysema is not known [133].

11.2.2. Coils. Self-activating coils are placed into the airway to induce atelectasis and volume reduction by assuming their preformed coil shape and bending the airway and collapsing the surrounding lung tissue.

In a pilot study [144], coils (PneumRx, Inc.; Mountain View, CA) were bronchoscopically placed bilaterally into the most diseased areas of lungs to achieve BLVR.

Eleven patients, of whom 8 with homogeneous and 3 with heterogeneous emphysema, underwent 21 treatments with 
a total of 101 coils placed. Adverse events included dyspnea in 10 instances, cough in 5 instances, COPD exacerbations in 3 instances, and chest pain in one. Improvements in $\mathrm{FEV}_{1}$, RV, TLC, SGRQ, and 6MWT were observed at one and three months following the first procedure. The greatest relative changes were observed in 6MWT, SGRQ and dyspnea score in the patients with heterogeneous emphysema.

In a more recent study Slebos and coworkers [145] reported on 12 patients with severe heterogeneous emphysema who underwent a staged bilateral (8 patients) or a unilateral (4 patients) treatment. 216 coils were implanted with a median of 10 coils per procedure. At 6 months postprocedure, $\mathrm{FEV}_{1}, \mathrm{FVC}, \mathrm{RV}, 6 \mathrm{MWT}$, and SGRQ improved significantly.

There were no life-threatening complications and adverse events included mild hemoptysis which occurred in $75 \%$ of the procedures, transient chest pain in 4 cases, and a spontaneously resolving pneumothorax in one case.

One theoretical advantage of coils over the use of valves is that they might confer benefit to patients with heterogeneous emphysema, independent of collateral ventilation. Potential disadvantages include uncertainty regarding removability of this devices long after deployment and the finding that an incompletely defined minimal amount of tissue is required for optimal performance of coils so that radiologic evidence of too severe emphysema or of giant bullae contraindicate the procedure [133].

11.2.3. Vapor Ablation. Bronchial thermal vapor ablation (BTVA; Uptake Medical Corp., Seattle) involves the bronchoscopic application of thermal energy to targeted areas of emphysema. BTVA induced injury triggers an inflammatory response in the airway and lung tissue, which eventually result in BLVR. BTVA utilizes a vapor generator and metal balloon vapor catheter, with target dosing at $3-7.5 \mathrm{cal} / \mathrm{g}$ according to a prior CT based tissue-air algorithm [133].

In a pilot study by Snell et al. [36], 11 patients with heterogeneous emphysema underwent 9 right and 2 left upper lobe unilateral treatments with approximately 3 applications per lobe. Immediate mild opacification in the target areas was always demonstrated by chest X-ray and all patients could be discharged after $24-48$ hours. Serious adverse events requiring hospitalization included COPD exacerbations in 2 patients whereas bacterial pneumonia, anxiety, and atrial tachycardia occurred in one patient each. Minor adverse events not requiring hospitalization included hemoptysis in 6 patient and inflammatory pneumonitis in 2 .

All patients had an improvement in dyspnea at 3-16 weeks posttreatment. Amongst 7 patients who completed 1month follow-up, the mean increase in $\mathrm{FEV}_{1}$ was $9 \%$ and the decrease in RV was 7.4\%. However, at 6 months there was no difference compared to baseline in $\mathrm{FEV}_{1}, \mathrm{FVC}$, and 6MWT. In contrast, dyspnea score and SGRQ improved both.

More recently, in a larger study, Snell and coworkers [146] reported on 44 patients with heterogeneous upperlobe emphysema in whom a higher dose of vapor was administered (10 cal/g of lung tissue) and a total of 72 and 58 segments were treated in the right upper lobe and left upper lobe, respectively. At 6 months, there was a significant improvement in $\mathrm{FEV}_{1}$, FVC, RV, 6MWT, SGRQ, and dyspnea index. After 6 months, the CT measurement of lobar volume was reduced by $48 \%$. Lobar fissure integrity had no or minimal influence on overall results. Major adverse events included COPD exacerbations, pneumonia, respiratory tract infections, and hemoptysis which resolved with medical therapy, except for 1 patient who died secondary to a COPD exacerbation.

11.3. Airway Bypass. The technique of airway bypass (Exhale Emphysema Treatment System, Broncus Technologies Inc., Mountain View, CA, USA) is based on the creation of extraanatomic passages between the hyperinflated lung tissue and larger airways, with the aim of facilitating expiration and decreasing air trapping. The system is based on multiple components including a Doppler flexible probe with an ultrasonic transducer at its tip, to help identify blood vessel-free bronchial areas. Following some pilot studies, which demonstrated the safety of the technique, short-lasting improvement in functional parameters has been reported after the creation of bypasses in few studies [27, 147, 148]. Recently, Shah and coworkers [149] reported the results of a randomized, double-blind, sham-controlled study (EASE trial) on 315 patients with homogeneous emphysema and severe hyperinflation of whom 208 underwent airway bypass and 107 sham control. One patient died posttreatment due to massive hemoptysis. One month after treatment SGRQ score improved significantly but at 6 months no differences were seen between the study arms in $\mathrm{FEV}_{1}, \mathrm{FVC}, \mathrm{RV}, 6 \mathrm{MWT}$, and SGRQ. Conclusion of the study was that airway bypass is unable to provide sustainable benefit in patients with severe homogeneous emphysema.

\section{Future Perspectives}

Data accumulated over the last two decades have definitively shown that LVRS can be highly effective in improving for up to several years respiratory function, exercise capacity, and quality of life in selected patients with severe emphysema.

Akuthota et al. [150] have recently noted that even when considering, as strict favorable markers for LVRS, the CTbased evidence of emphysema involving $40 \%$ or greater of the overall lung volume with a predominant upper-lobe distribution of disease, $15 \%$ of COPD patients with functional status staged as class III or IV according to the GOLD classification met criteria for LVRS. Nonetheless, despite a significant number of potential candidates, this surgical modality has progressively declined in use in the last years. Several conjectural reasons have been proposed to explain such an unexpected finding.

First, LVRS assessment has been perceived as overly complicated; second, many physicians are probably still unaware of the proper indications and benefits of LVRS; third, the NETT publication [49] reporting on the patient group at high risk for death with LVRS might have been misinterpreted as indicating generalized poor results for a high-risk procedure, and, finally, LVRS has been considered too costly $[23,151]$. 
I would add that, at least in some instances, the availability of novel investigational BLVR methods, the efficacy of which is not yet proven, may have contributed to orient or possibly disorient the patients demand.

What clearly emerges from the literature is that the Achilles heel of LVRS is not attributable to doubts on clinical efficacy but rather to the significant perioperative morbidity of this treatment modality.

In this respect, I believe that the main triggering factors of LVRS-related morbidity include both adverse effects of general anesthesia with mechanical ventilation and the use of a resectional method entailing excision of wide portions of extremely fragile lung tissue [20].

As a result, further investigation aimed at developing less invasive strategies and methods that might allow to achieve long-term results as satisfactory as those shown by resectional LVRS but with a lower morbidity will be helpful.

In particular, a more thorough understanding of the pros and cons of a unilateral or staged bilateral LVRS strategy might contribute to reduce mortality and morbidity while assuring durable benefits.

Moreover, further results on use of novel options including the nonresectional LVRS method, which avoids any removal of lung tissue and can be performed in spontaneously ventilating subjects, as well as on the different novel BLVR methods that can be performed in a nearly ambulatory setting, are awaited and will be helpful to define a framework of alternative or complimentary treatment options.

Lung transplantation represents the only reliable therapy for a specific subset of patients as those with homogeneous emphysema associated with a too impaired respiratory function whereas in other instances it can represent a valid alternative to LVRS or can be included in a strategy, which combines both modalities.

Hopefully, the evolving scenario will prompt creation of noncompeting multidisciplinary teams including anesthesiologists, pulmonologists, radiologists, and thoracic surgeons, who will work together not only to optimize the results of LVRS but also to define by consensus, composite algorithms of treatment including different effective treatment methods.

\section{Conclusion}

This literature review indicates that LVRS is a highly effective palliative treatment modality for severe emphysema, particularly for those individuals who have CT evidence of heterogeneous upper-lobe predominant disease associated with impaired exercise capacity. By the application of different strategies of treatment including one-stage bilateral, unilateral and staged surgical approaches, significant and long-lasting improvements can occur in respiratory function, exercise capacity, and quality of life.

Mortality and morbidity of LVRS have been not negligible but novel surgical and BLVR methods are under active scrutiny and hold promise as reliably effective and as yet less invasive options.

Overall, it is worth noting that so far all novel investigative methods, even if based on different mechanisms of action, continue to respect an apparently paradoxical concept ideated more than 50 years ago [38], which suggested that patients suffering from the distressing effects of severe emphysema may greatly improve clinically and functionally by reducing their overall lungs' volume.

Such a genial concept warrants readily accepted, safely accomplished, well tolerated, and durably effective applicative methods.

\section{Conflict of Interests}

The author declares that there is no conflict of interests regarding the publication of this paper.

\section{Acknowledgments}

I thank Professor Giovanni Simonetti and Professor Gianluigi Sergiacomi for permission to use the images acquired in the Department of Diagnostic Imaging, Molecular Imaging, Radiotherapy and Interventional Radiology of the Tor Vergata University. I also greatly thank all the participants to the expert meeting on interventional emphysema treatment organized by Professor Walter Weder and Professor Feliz Herth in Zurich (November 7-9, 2013), who inspired my final considerations on the future perspectives of LVRS.

\section{References}

[1] R. J. Halbert, J. L. Natoli, A. Gano, E. Badamgarav, A. S. Buist, and D. M. Mannino, "Global burden of COPD: systematic review and meta-analysis," European Respiratory Journal, vol. 28, no. 3, pp. 523-532, 2006.

[2] "Terminology, definitions and classification of chronic pulmonary emphysema and related conditions, Ciba symposium," Thorax, vol. 14, pp. 286-299, 1959.

[3] D. E. O’Donnell, M. Lam, and K. A. Webb, "Measurement of symptoms, lung hyperinflation, and endurance during exercise in chronic obstructive pulmonary disease," The American Journal of Respiratory and Critical Care Medicine, vol. 158, no. 5, pp. 1557-1565, 1998.

[4] D. E. O’Donnell, S. M. Revill, and K. A. Webb, "Dynamic hyperinflation and exercise intolerance in chronic obstructive pulmonary disease," The American Journal of Respiratory and Critical Care Medicine, vol. 164, no. 5, pp. 770-777, 2001.

[5] A. Jubran and M. J. Tobin, "Pathophysiologic basis of acute respiratory distress in patients who fail a trial of weaning from mechanical ventilation," The American Journal of Respiratory and Critical Care Medicine, vol. 155, no. 3, pp. 906-915, 1997.

[6] C. Casanova, C. Cote, J. P. de Torres et al., "Inspiratory-tototal lung capacity ratio predicts mortality in patients with chronic obstructive pulmonary disease," The American Journal of Respiratory and Critical Care Medicine, vol. 171, no. 6, pp. 591597, 2005.

[7] J. D. Cooper, E. P. Trulock, A. N. Triantafillou et al., "Bilateral pneumectomy (volume reduction) for chronic obstructive pulmonary disease," Journal of Thoracic and Cardiovascular Surgery, vol. 109, no. 1, pp. 106-119, 1995.

[8] A. F. Gelb, R.J. McKenna Jr., M. Brenner, J. D. Epstein, and $\mathrm{N}$. Zamel, "Lung function $5 \mathrm{yr}$ after lung volume reduction 
surgery for emphysema," The American Journal of Respiratory and Critical Care Medicine, vol. 163, no. 7, pp. 1562-1566, 2001.

[9] A. M. Ciccone, B. F. Meyers, T. J. Guthrie et al., "Long-term outcome of bilateral lung volume reduction in 250 consecutive patients with emphysema," Journal of Thoracic and Cardiovascular Surgery, vol. 125, no. 3, pp. 513-525, 2003.

[10] K. S. Naunheim, D. E. Wood, Z. Mohsenifar et al., "Longterm follow-up of patients receiving lung-volume-reduction surgery versus medical therapy for severe emphysema by the national emphysema treatment trial research group," The Annals of Thoracic Surgery, vol. 82, no. 2, pp. 431-443, 2006.

[11] T. C. Mineo, E. Pompeo, D. Mineo, P. Rogliani, C. Leonardis, and I. Nofroni, "Results of unilateral lung volume reduction surgery in patients with distinct heterogeneity of emphysema between lungs," Journal of Thoracic and Cardiovascular Surgery, vol. 129, no. 1, pp. 73-79, 2005.

[12] E. Pompeo and T. C. Mineo, "Two-year improvement in multidimensional body mass index, airflow obstruction, dyspnea, and exercise capacity index after nonresectional lung volume reduction surgery in awake patients," The Annals of Thoracic Surgery, vol. 84, no. 6, pp. 1862-1869, 2007.

[13] W. Weder, M. Tutic, D. Lardinois et al., "Persistent benefit from lung volume reduction surgery in patients with homogeneous emphysema," The Annals of Thoracic Surgery, vol. 87, no. 1, pp. 229-237, 2009.

[14] G. J. Criner, F. C. Cordova, S. Furukawa et al., "Prospective randomized trial comparing bilateral lung volume reduction surgery to pulmonary rehabilitation in severe chronic obstructive pulmonary disease," The American Journal of Respiratory and Critical Care Medicine, vol. 160, no. 6, pp. 2018-2027, 1999.

[15] D. Geddes, M. Davies, H. Koyama et al., "Effect of lung-volumereduction surgery in patients with severe emphysema," The New England Journal of Medicine, vol. 343, no. 4, pp. 239-245, 2000.

[16] E. Pompeo, M. Marino, I. Nofroni, G. Matteucci, and T. C. Mineo, "Reduction pneumoplasty versus respiratory rehabilitation in severe emphysema: a randomized study," The Annals of Thoracic Surgery, vol. 70, no. 3, pp. 948-954, 2000.

[17] R. S. Goldstein, T. R. J. Todd, G. Guyatt et al., "Influence of lung volume reduction surgery (LVRS) on health related quality of life in patients with chronic obstructive pulmonary disease," Thorax, vol. 58, no. 5, pp. 405-410, 2003.

[18] G. Hillerdal, C.-G. Löfdahl, K. Ström et al., "Comparison of lung volume reduction surgery and physical training on health status and physiologic outcomes: a randomized controlled clinical trial," Chest, vol. 128, no. 5, pp. 3489-3499, 2005.

[19] J. D. Miller, R. A. Malthaner, C. H. Goldsmith et al., "A randomized clinical trial of lung volume reduction surgery versus best medical care for patients with advanced emphysema: a two-year study from Canada," The Annals of Thoracic Surgery, vol. 81, no. 1, pp. 314-321, 2006.

[20] E. Pompeo, P. Rogliani, F. Tacconi et al., "Randomized comparison of awake nonresectional versus nonawake resectional lung volume reduction surgery," Journal of Thoracic and Cardiovascular Surgery, vol. 143, no. 1, pp. 47-54, 2012.

[21] A. Fishman, F. Martinez, K. Naunheim et al., "A randomized trial comparing lung-volume-reduction surgery with medical therapy for severe emphysema," The New England Journal of Medicine, vol. 348, no. 21, pp. 2059-2073, 2003.

[22] M. M. DeCamp Jr., R. J. McKenna Jr., C. C. Deschamps, and M. J. Krasna, "Lung volume reduction surgery: technique, operative mortality, and morbidity," Proceedings of the American Thoracic Society, vol. 5, no. 4, pp. 442-446, 2008.
[23] National Emphysema Treatment Trial Research Group, "Cost effectiveness of lung-volume-reduction surgery for patients with severe emphysema," The New England Journal of Medicine, vol. 348, pp. 2092-2102, 2003.

[24] E. P. Ingenito, J. J. Reilly, S. J. Mentzer et al., "Bronchoscopic volume reduction: a safe and effective alternative to surgical therapy for emphysema," The American Journal of Respiratory and Critical Care Medicine, vol. 164, no. 2, pp. 295-301, 2001.

[25] T. P. Toma, N. S. Hopkinson, J. Hillier et al., "Bronchoscopic volume reduction with valve implants in patients with severe emphysema," The Lancet, vol. 361, no. 9361, pp. 931-933, 2003.

[26] Y. Watanabe, K. Matsuo, A. Tamaoki, R. Komoto, and S. Hiraki, "Bronchial occlusion with endobronchial watanabe spigot," Journal of Bronchology, vol. 10, no. 4, pp. 264-267, 2003.

[27] E. A. Rendina, T. de Giacomo, F. Venuta et al., "Feasibility and safety of the airway bypass procedure for patients with emphysema," Journal of Thoracic and Cardiovascular Surgery, vol. 125, no. 6, pp. 1294-1299, 2003.

[28] E. P. Ingenito, R. L. Berger, A. C. Henderson, J. J. Reilly, L. Tsai, and A. Hoffman, "Bronchoscopic lung volume reduction using tissue engineering principles," The American Journal of Respiratory and Critical Care Medicine, vol. 167, no. 5, pp. 771778, 2003.

[29] G. I. Snell, L. Holsworth, Z. L. Borrill et al., “The potential for bronchoscopic lung volume reduction using bronchial prostheses: a pilot study," Chest, vol. 124, no. 3, pp. 1073-1080, 2003.

[30] C. K. Choong, F. J. Haddad, E. Y. Gee, and J. D. Cooper, "Feasibility and safety of airway bypass stent placement and influence of topical mitomycin C on stent patency," Journal of Thoracic and Cardiovascular Surgery, vol. 129, no. 3, pp. 632638, 2005.

[31] I. Y. P. Wan, T. P. Toma, D. M. Geddes et al., "Bronchoscopic lung volume reduction for end-stage emphysema: report on the first 98 patients," Chest, vol. 129, no. 3, pp. 518-526, 2006.

[32] F. C. Sciurba, A. Ernst, F. J. F. Herth et al., "A randomized study of endobronchial valves for advanced emphysema," The New England Journal of Medicine, vol. 363, no. 13, pp. 1233-1244, 2010.

[33] G. J. Criner, V. Pinto-Plata, C. Strange et al., "Biologic lung volume reduction in advanced upper lobe emphysema phase 2 results," The American Journal of Respiratory and Critical Care Medicine, vol. 179, no. 9, pp. 791-798, 2009.

[34] Y. Refaely, M. Dransfield, M. R. Kramer et al., "Biologic lung volume reduction therapy for advanced homogeneous emphysema," European Respiratory Journal, vol. 36, no. 1, pp. 20-27, 2010.

[35] F. J. F. Herth, R. Eberhard, D. Gompelmann, D.-J. Slebos, and A. Ernst, "Bronchoscopic lung volume reduction with a dedicated coil: a clinical pilot study," Therapeutic Advances in Respiratory Disease, vol. 4, no. 4, pp. 225-231, 2010.

[36] G. I. Snell, P. Hopkins, G. Westall, L. Holsworth, A. Carle, and T. J. Williams, "A feasibility and safety study of bronchoscopic thermal vapor ablation: a novel emphysema therapy," The Annals of Thoracic Surgery, vol. 88, no. 6, pp. 1993-1998, 2009.

[37] R. Saad Jr., V. D. Neto, M. Botter, R. Stirbulov, J. H. Rivaben, and R. Gonçalves, "Therapeutic application of collateral ventilation with pulmonary drainage in the treatment of diffuse emphysema: report of the first three cases," Jornal Brasileiro de Pneumologia, vol. 35, no. 1, pp. 14-19, 2009. 
[38] O. C. Brantigan and E. Mueller, "Surgical treatment of pulmonary emphysema," The American Surgeon, vol. 23, no. 9, pp. 789-804, 1957.

[39] O. C. Brantigan, E. Mueller, and M. B. Kress, "A surgical approach to pulmonary emphysema," The American Review of Respiratory Disease, vol. 80, no. 1, pp. 194-206, 1959.

[40] O. C. Brantigan, M. B. Kress, and E. A. Mueller, "The surgical approach to pulmonary emphysema," Chest, vol. 39, no. 5, pp. 485-499, 1961.

[41] R. J. Keenan, R. J. Landreneau, F. C. Sciurba et al., "Unilateral thoracoscopic surgical approach for diffuse emphysema," Journal of Thoracic and Cardiovascular Surgery, vol. 111, no. 2, pp. 308-316, 1996.

[42] T. C. Mineo, E. Pompeo, G. Simonetti et al., "Unilateral thoracoscopic reduction pneumoplasty for asymmetric emphysema," European Journal of Cardio-Thoracic Surgery, vol. 14, no. 1, pp. 33-39, 1998.

[43] R. M. Kotloff, G. Tino, H. I. Palevsky et al., "Comparison of short-term functional outcomes following unilateral and bilateral lung volume reduction surgery," Chest, vol. 113, no. 4, pp. 890-895, 1998.

[44] R. Bingisser, A. Zollinger, M. Hauser, K. E. Bloch, E. W. Russi, and W. Weder, "Bilateral volume reduction surgery for diffuse pulmonary emphysema by video-assisted thoracoscopy," Journal of Thoracic and Cardiovascular Surgery, vol. 112, no. 4, pp. 875-882, 1996.

[45] R. J. McKenna Jr., M. Brenner, A. F. Gelb et al., "A randomized, prospective trial of stapled lung reduction versus laser bullectomy for diffuse emphysema," Journal of Thoracic and Cardiovascular Surgery, vol. 111, no. 2, pp. 317-322, 1996.

[46] R. M. Kotloff, G. Tino, J. E. Bavaria et al., "Bilateral lung volume reduction surgery for advanced emphysema: a comparison of median sternotomy and thoracoscopic approaches," Chest, vol. 110, no. 6, pp. 1399-1406, 1996.

[47] S. R. Hazelrigg, T. M. Boley, M. J. Magee, C. H. Lawyer, and J. Q. Henkle, "Comparison of staged thoracoscopy and median sternotomy for lung volume reduction," The Annals of Thoracic Surgery, vol. 66, no. 4, pp. 1134-1139, 1998.

[48] R.J. McKenna Jr., M. Brenner, R. J. Fischel et al., "Patient selection criteria for lung volume reduction surgery," Journal of Thoracic and Cardiovascular Surgery, vol.114, no. 6, pp. 957-967, 1997.

[49] National Emphysema Treatment Trial Research Group, "Patients at high risk of death after lung-volumereduction surgery," The New England Journal of Medicine, vol. 345, pp. 1075-1083, 2001.

[50] E. P. Ingenito, R. B. Evans, S. H. Loring et al., "Relation between preoperative inspiratory lung resistance and the outcome of lung-volume-reduction surgery for emphysema," The New England Journal of Medicine, vol. 338, no. 17, pp. 1181-1185, 1998.

[51] G. R. Washko, G. J. Criner, Z. Mohsenifar et al., "Computed tomographic-based quantification of emphysema and correlation to pulmonary function and mechanics," Journal of Chronic Obstructive Pulmonary Disease, vol. 5, no. 3, pp. 177-186, 2008.

[52] R. Benzo, "Lung volume reduction surgery: non-pharmacological approach," Current Opinion in Anaesthesiology, vol. 24, pp. 44-48, 2011.

[53] S. H. Loring, D. E. Leith, M. J. Connotti et al., "Model of functional restriction in chronic obstructive pulmonary disease, transplantation and lung reduction surgery," The American Journal of Respiratory and Critical Care Medicine, vol. 160, pp. 821-828, 1999.
[54] F. J. Martinez, M. M. de Oca, R. I. Whyte, J. Stetz, S. E. Gay, and B. R. Celli, "Lung-volume reduction improves dyspnea, dynamic hyperinflation, and respiratory muscle function," The American Journal of Respiratory and Critical Care Medicine, vol. 155, no. 6, pp. 1984-1990, 1997.

[55] R. B. Gorman, D. K. McKenzie, J. E. Butler, J. F. Tolman, and S. C. Gandevia, "Diaphragm length and neural drive after lung volume reduction surgery," The American Journal of Respiratory and Critical Care Medicine, vol. 172, no. 10, pp. 1259-1266, 2005.

[56] F. C. Sciurba, R. M. Rogers, R. J. Keenan et al., "Improvement in pulmonary function and elastic recoil after lung reduction surgery for diffuse emphysema," The New England Journal of Medicine, vol. 334, pp. 1095-1099, 1996.

[57] A. F. Gelb, N. Zamel, R. J. Mckenna Jr., and M. Brenner, "Mechanism of short-term improvement in lung function after emphysema resection," The American Journal of Respiratory and Critical Care Medicine, vol. 154, no. 4 I, pp. 945-951, 1996.

[58] E. P. Ingenito, S. H. Loring, M. L. Moy, S. J. Mentzer, S. J. Swanson, and J. J. Reilly, "Interpreting improvement in expiratory flows after lung volume reduction surgery in terms of flow limitation theory," The American Journal of Respiratory and Critical Care Medicine, vol. 163, no. 5, pp. 1074-1080, 2001.

[59] H. E. Fessler and S. Permutt, "Lung volume reduction surgery and airflow limitation," The American Journal of Respiratory and Critical Care Medicine, vol. 157, no. 3, part 1, pp. 715-722, 1998.

[60] E. M. Tschernko, W. Wisser, T. Wanke et al., "Changes in ventilatory mechanics and diaphragmatic function after lung volume reduction surgery in patients with COPD," Thorax, vol. 52, no. 6, pp. 545-550, 1997.

[61] Y. Lando, P. M. Boiselle, D. Shade et al., "Effect of lung volume reduction surgery on diaphragm length in severe chronic obstructive pulmonary disease," The American Journal of Respiratory and Critical Care Medicine, vol. 159, no. 3, pp. 796805, 1999.

[62] M. Cassart, J. Hamacher, Y. Verbandt et al., "Effects of lung volume reduction surgery for emphysema on diaphragm dimensions and configuration," The American Journal of Respiratory and Critical Care Medicine, vol. 163, no. 5, pp. 1171-1175, 2001.

[63] K. E. Bloch, Y. Li, J. Zhang et al., "Effect of surgical lung volume reduction on breathing patterns in severe pulmonary emphysema," The American Journal of Respiratory and Critical Care Medicine, vol. 156, no. 2, part 1, pp. 553-560, 1997.

[64] M. Oswald-Mammosser, R. Kessler, G. Massard, J.-M. Wihlm, E. Weitzenblum, and J. Lonsdorfer, "Effect of lung volume reduction surgery on gas exchange and pulmonary hemodynamics at rest and during exercise," The American Journal of Respiratory and Critical Care Medicine, vol. 158, no. 4, pp. 10201025, 1998.

[65] M. L. Snyder, C. H. Goss, B. Neradilek et al., "Changes in arterial oxygenation and self-reported oxygen use after lung volume reduction surgery," The American Journal of Respiratory and Critical Care Medicine, vol. 178, no. 4, pp. 339-345, 2008.

[66] G. Cremona, J. A. Barbara, T. Melgosa et al., "Mechanisms of gas exchange response to lung volume reduction surgery in severe emphysema," Journal of Applied Physiology, vol. 110, no. 4, pp. 1036-1045, 2011.

[67] W. Huang, W. R. Wang, B. Deng et al., "Several clinical interests regarding lung volume reduction surgery for severe emphysema: meta-analysis and systematic review of randomized controlled trials," Journal of Cardiothoracic Surgery, vol. 6, no. 1, article 148, 2011. 
[68] G. J. Criner, P. Belt, A. L. Sternberg et al., "Effects of lung volume reduction surgery on gas exchange and breathing pattern during maximum exercise," Chest, vol. 135, no. 5, pp. 1268-1279, 2009.

[69] T. Takayama, C. Shindoh, Y. Kurokawa et al., "Effects of lung volume reduction surgery for emphysema on oxygen cost of breathing," Chest, vol. 123, no. 6, pp. 1847-1852, 2003.

[70] T. C. Mineo, E. Pompeo, D. Mineo, V. Ambrogi, D. Ciarapica, and A. Polito, "Resting energy expenditure and metabolic changes after lung volume reduction surgery for emphysema," The Annals of Thoracic Surgery, vol. 82, no. 4, pp. 1205-1211, 2006.

[71] T. C. Mineo, E. Pompeo, P. Rogliani et al., "Effect of lung volume reduction surgery for severe emphysema on right ventricular function," The American Journal of Respiratory and Critical Care Medicine, vol. 165, no. 4, pp. 489-494, 2002.

[72] K. Jörgensen, E. Houltz, U. Westfelt, F. Nilsson, H. Scherstén, and S.-E. Ricksten, "Effects of lung volume reduction surgery on left ventricular diastolic filling and dimensions in patients with severe emphysema," Chest, vol. 124, no. 5, pp. 1863-1870, 2003.

[73] G. J. Criner, S. M. Scharf, J. A. Falk et al., "Effect of lung volume reduction surgery on resting pulmonary hemodynamics in severe emphysema," The American Journal of Respiratory and Critical Care Medicine, vol. 176, no. 3, pp. 253-260, 2007.

[74] I. L. Weg, L. Rossoff, K. McKeon, L. M. Graver, and S. M. Scharf, "Development of pulmonary hypertension after lung volume reduction surgery," The American Journal of Respiratory and Critical Care Medicine, vol. 159, no. 2, pp. 552-556, 1999.

[75] R.J. McKenna Jr., M. Brenner, R. J. Fischel, and A. F. Gelb, "Should lung volume reduction for emphysema be unilateral or bilateral?” Journal of Thoracic and Cardiovascular Surgery, vol. 112, no. 5, pp. 1331-1339, 1996.

[76] National Emphysema Treatment Trial Research Group, "Safety and efficacy of median sternotomy versus video-assisted thoracic surgery for lung volume reduction surgery," The Journal of Thoracic and Cardiovascular Surgery, vol. 127, pp. 1350-1360, 2004.

[77] M. de Perrot, M. Licker, and A. Spiliopoulos, "Muscle-sparing anterior thoracotomy for one-stage bilateral lung volume reduction operation," The Annals of Thoracic Surgery, vol. 66, no. 2, pp. 582-584, 1998.

[78] M. Argenziano, B. Thomashow, P. A. Jellen et al., "Functional comparison of unilateral versus bilateral lung volume reduction surgery," The Annals of Thoracic Surgery, vol. 64, no. 2, pp. 321327, 1997.

[79] T. C. Mineo, E. Pompeo, P. Rogliani, S. Villaschi, C. Pistolese, and C. Simonetti, "Thoracoscopic reduction pneumoplasty for severe emphysema: do pleural adhesions affect outcome?" Thoracic and Cardiovascular Surgeon, vol. 47, no. 5, pp. 288-292, 1999.

[80] F. Tacconi, E. Pompeo, and T. C. Mineo, "Late-onset occult pneumothorax after lung volume-reduction surgery," The Annals of Thoracic Surgery, vol. 80, no. 6, pp. 2008-2012, 2005.

[81] I. Oey and D. A. Waller, "Metalloptysis: a late complication of lung volume reduction surgery," The Annals of Thoracic Surgery, vol. 71, no. 5, pp. 1694-1695, 2001.

[82] M. Iqbal, L. Rossoff, K. McKeon, M. Graver, and S. M. Scharf, "Development of a giant bulla after lung volume reduction surgery," Chest, vol. 116, no. 6, pp. 1809-1811, 1999.

[83] K. S. Naunheim, D. E. Wood, M. J. Krasna et al., "Predictors of operative mortality and cardiopulmonary morbidity in the national emphysema treatment trial," Journal of Thoracic and Cardiovascular Surgery, vol. 131, no. 1, pp. 43-53, 2006.

[84] M. M. DeCamp, E. H. Blackstone, K. S. Naunheim et al., "Patient and surgical factors influencing air leak after lung volume reduction surgery: lessons learned from the national emphysema treatment trial," The Annals of Thoracic Surgery, vol. 82, no. 1, pp. 197-207, 2006.

[85] J. D. Cooper, G. A. Patterson, R. S. Sundaresan et al., "Results of 150 consecutive bilateral lung volume reduction procedures in patients with severe emphysema," Journal of Thoracic and Cardiovascular Surgery, vol. 112, no. 5, pp. 1319-1330, 1996.

[86] R. J. Fischel and R. J. McKenna Jr., "Bovine pericardium versus bovine collagen to buttress staples for lung reduction operations," The Annals of Thoracic Surgery, vol. 65, no. 1, pp. 217-219, 1998.

[87] P. A. Thistlethwaite, J. D. Luketich, P. F. Ferson, R. J. Keenan, and S. W. Jamieson, "Ablation of persistent air leaks after thoracic procedures with fibrin sealant," The Annals of Thoracic Surgery, vol. 67, no. 2, pp. 575-577, 1999.

[88] W. S. Horsley and J. I. Miller Jr., "Management of the uncontrollable pulmonary air leak with cyanoacrylate glue," The Annals of Thoracic Surgery, vol. 63, no. 5, pp. 1492-1493, 1997.

[89] J. C. Wain, L. R. Kaiser, D. W. Johnstone et al., "Trial of a novel synthetic sealant in preventing air leaks after lung resection," The Annals of Thoracic Surgery, vol. 71, no. 5, pp. 1623-1629, 2001.

[90] S. R. Hazelrigg, T. M. Boley, K. S. Naunheim et al., "Effect of bovine pericardial strips on air leak after stapled pulmonary resection," The Annals of Thoracic Surgery, vol. 63, no. 6, pp. 1573-1575, 1997.

[91] U. Stammberger, W. Klepetko, G. Stamatis et al., "Buttressing the staple line in lung volume reduction surgery: a randomized three-center study," The Annals of Thoracic Surgery, vol. 70, no. 6, pp. 1820-1825, 2000.

[92] F. Tacconi, E. Pompeo, and T. C. Mineo, "Duration of air leak is reduced after awake nonresectional lung volume reduction surgery," European Journal of Cardio-Thoracic Surgery, vol. 35, no. 5, pp. 822-828, 2009.

[93] C. A. Keller, G. Ruppel, A. Hibbett, J. Osterloh, and K. S. Naunheim, "Thoracoscopic lung volume reduction surgery reduces dyspnea and improves exercise capacity in patients with emphysema," The American Journal of Respiratory and Critical Care Medicine, vol. 156, no. 1, pp. 60-67, 1997.

[94] M. L. Moy, E. P. Ingenito, S. J. Mentzer, R. B. Evans, and J. J. Reilly Jr., "Health-related quality of life improves following pulmonary rehabilitation and lung volume reduction surgery," Chest, vol. 115, no. 2, pp. 383-389, 1999.

[95] J. Hamacher, S. Büchi, C. L. Georgescu et al., "Improved quality of life after lung volume reduction surgery," European Respiratory Journal, vol. 19, no. 1, pp. 54-60, 2002.

[96] T. C. Mineo, V. Ambrogi, E. Pompeo et al., "Impact of lung volume reduction surgery versus rehabilitation on quality of life," European Respiratory Journal, vol. 23, no. 2, pp. 275-280, 2004.

[97] R. Benzo, M. H. Farrell, C.-C. H. Chang et al., "Integrating health status and survival data: the palliative effect of lung volume reduction surgery," The American Journal of Respiratory and Critical Care Medicine, vol. 180, no. 3, pp. 239-246, 2009.

[98] T. C. Mineo, V. Ambrogi, E. Pompeo, P. Bollero, D. Mineo, and I. Nofroni, "Body weight and nutritional changes after reduction pneumoplasty for severe emphysema: a randomized 
study," Journal of Thoracic and Cardiovascular Surgery, vol. 124, no. 4, pp. 660-667, 2002.

[99] D. Mineo, V. Ambrogi, V. Lauriola, E. Pompeo, and T. C. Mineo, "Recovery of body composition improves long-term outcomes after lung volume reduction surgery for emphysema," European Respiratory Journal, vol. 36, no. 2, pp. 408-416, 2010.

[100] E. Kozora, C. F. Emery, M. C. Ellison, F. S. Wamboldt, P. T. Diaz, and B. Make, "Improved neurobehavioral functioning in emphysema patients following lung volume reduction surgery compared with medical therapy," Chest, vol. 128, no. 4, pp. $2653-$ 2663, 2005.

[101] S. Homan, S. Porter, M. Peacock, N. Saccoia, A. M. Southcott, and R. Ruffin, "Increased effective lung volume following lung volume reduction surgery in emphysema," Chest, vol. 120, no. 4 , pp. 1157-1162, 2001.

[102] M. R. Lammi, N. Marchetti, S. Barnett, and G. J. Criner, "Heterogeneity of lung volume reduction surgery outcomes in patients selected by use of evidence-based criteria," The Annals of Thoracic Surgery, vol. 95, no. 6, pp. 1905-1911, 2013.

[103] G. R. Washko, V. S. Fan, S. D. Ramsey et al., "The effect of lung volume reduction surgery on chronic obstructive pulmonary disease exacerbations," The American Journal of Respiratory and Critical Care Medicine, vol. 177, no. 2, pp. 164-169, 2008.

[104] H. F. Armstrong, J. Gonzalez-Costello, U. P. Jorde et al., "The effect of lung volume reduction surgery on chronotropic incompetence," Respiratory Medicine, vol. 106, pp. 1389-1395, 2012.

[105] D. Chandra, D. A. Lipson, E. A. Hoffman et al., "Perfusion scintigraphy and patient selection for lung volume reduction surgery," The American Journal of Respiratory and Critical Care Medicine, vol. 182, no. 7, pp. 937-946, 2010.

[106] I. F. Oey, D. A. Waller, S. Bal, S. J. Singh, T. J. Spyt, and M. D. L. Morgan, "Lung volume reduction surgery-a comparison of the long term outcome of unilateral vs. bilateral approaches," European Journal of Cardio-Thoracic Surgery, vol. 22, no. 4, pp. 610-614, 2002.

[107] M. Brenner, R. J. McKenna Jr., A. F. Gelb, R. J. Fischel, and A. F. Wilson, "Rate of FEV1 change following lung volume reduction surgery," Chest, vol. 113, no. 3, pp. 652-659, 1998.

[108] R. J. McKenna Jr., A. Gelb, and M. Brenner, "Lung volume reduction surgery for chronic obstructive pulmonary disease: where do we stand?" World Journal of Surgery, vol. 25, no. 2, pp. 231-237, 2001.

[109] R.J. McKenna Jr., M. Brenner, R. J. Fischel, and A. F. Gelb, "Should lung volume reduction for emphysema be unilateral or bilateral?" Journal of Thoracic and Cardiovascular Surgery, vol. 112, no. 5, pp. 1331-1339, 1996.

[110] M. D. Becker, Y. M. Berkmen, J. H. M. Austin et al., "Lung volumes before and after lung volume reduction surgery: quantitative CT analysis," The American Journal of Respiratory and Critical Care Medicine, vol. 157, no. 5, pp. 1593-1599, 1998.

[111] E. Pompeo, G. Sergiacomi, I. Nofroni, W. Roscetti, G. Simonetti, and T. C. Mineo, "Morphologic grading of emphysema is useful in the selection of candidates for unilateral or bilateral reduction pneumoplasty," European Journal of Cardio-Thoracic Surgery, vol. 17, no. 6, pp. 680-686, 2000.

[112] G. A. Lowdermilk, R. J. Keenan, R. J. Landreneau et al., "Comparison of clinical results for unilateral and bilateral thoracoscopic lung volume reduction," The Annals of Thoracic Surgery, vol. 69, no. 6, pp. 1670-1674, 2000.

[113] D. L. Serna, M. Brenner, K. E. Osann et al., "Survival after unilateral versus bilateral lung volume reduction surgery for emphysema," Journal of Thoracic and Cardiovascular Surgery, vol. 118, no. 6, pp. 1101-1109, 1999.

[114] K. S. Naunheim, L. R. Kaiser, J. E. Bavaria et al., "Longterm survival after thoracoscopic lung volume reduction: a multiinstitutional review," The Annals of Thoracic Surgery, vol. 68, no. 6, pp. 2026-2032, 1999.

[115] E. Pompeo and T. C. Mineo, "Long-term outcome of staged versus one-stage bilateral thoracoscopic reduction pneumoplasty," European Journal of Cardio-Thoracic Surgery, vol. 21, no. 4, pp. 627-633, 2002.

[116] B. F. Meyers and G. A. Patterson, "Chronic obstructive pulmonary disease - 10: bullectomy, lung volume reduction surgery, and transplantation for patients with chronic obstructive pulmonary disease," Thorax, vol. 58, no. 7, pp. 634-638, 2003.

[117] K. E. A. Burns, R. J. Keenan, W. F. Grgurich, J. D. Manzetti, and M. A. Zenati, "Outcomes of lung volume reduction surgery followed by lung transplantation: a matched cohort study," The Annals of Thoracic Surgery, vol. 73, no. 5, pp. 1587-1593, 2002.

[118] M. Tutic, D. Lardinois, S. Imfeld et al., "Lung-Volume Reduction Surgery as an Alternative or Bridging Procedure to Lung Transplantation," The Annals of Thoracic Surgery, vol. 82, no. 1, pp. 208-213, 2006.

[119] M. I. Hertz, D. O. Taylor, E. P. Trulock et al., "The registry of the international society for heart and lung transplantation: nineteenth official report-2002," Journal of Heart and Lung Transplantation, vol. 21, no. 9, pp. 950-970, 2002.

[120] M. Zenati, R. J. Keenan, R. J. Landreneau, I. L. Paradis, P. F. Ferson, and B. P. Griffith, "Lung reduction as bridge to lung transplantation in pulmonary emphysema," The Annals of Thoracic Surgery, vol. 59, no. 6, pp. 1581-1583, 1995.

[121] J. E. Bavaria, A. Pochettino, R. M. Kotloff et al., "Effect of volume reduction on lung transplant timing and selection for chronic obstructive pulmonary disease," Journal of Thoracic and Cardiovascular Surgery, vol. 115, no. 1, pp. 9-18, 1998.

[122] T. R. J. Todd, J. Perron, T. L. Winton, and S. H. Keshavjee, "Simultaneous single-lung transplantation and lung volume reduction," The Annals of Thoracic Surgery, vol. 63, no. 5, pp. 1468-1470, 1997.

[123] N. A. Yonan, A. El-Gamel, J. Egan, J. Kakadellis, A. Rahman, and A. K. Deiraniya, "Single lung transplantation for emphysema: predictors for native lung hyperinflation," Journal of Heart and Lung Transplantation, vol. 17, no. 2, pp. 192-201, 1998.

[124] E. Arango, D. Espinosa, J. Illana et al., "Lung volume reduction surgery after lung transplantation for emphysema-chronic obstructive pulmonary disease," Transplantation Proceedings, vol. 44, pp. 2115-2117, 2012.

[125] S. D. Nathan, L. B. Edwards, S. D. Barnett, S. Ahmad, and N. A. Burton, "Outcomes of COPD lung transplant recipients after lung volume reduction surgery," Chest, vol. 126, no. 5, pp. 15691574, 2004.

[126] N. Shigemura, S. Gilbert, J. K. Bhama et al., "Lung transplantation after lung volume reduction surgery," Transplantation, vol. 96, pp. 421-425, 2013.

[127] V. L. Crosa-Dorado, J. Pomi, and E. J. Perez-Penco, "Treatment of dyspnea in emphysema: pulmonary remodeling. Hemo- and pneumostatic suturing of the emphysematous lung," Research in Surgery, vol. 4, no. 3, pp. 1-4, 1992.

[128] S. J. Swanson, S. J. Mentzer, M. M. DeCamp Jr. et al., "No-cut thoracoscopic lung plication: a new technique for lung volume reduction surgery," Journal of the American College of Surgeons, vol. 185, no. 1, pp. 25-32, 1997. 
[129] M. Iwasaki, N. Nishiumi, K. Kaga, M. Kanazawa, I. Kuwahira, and H. Inoue, "Application of the fold plication method for unilateral lung volume reduction in pulmonary emphysema," The Annals of Thoracic Surgery, vol. 67, no. 3, pp. 815-817, 1999.

[130] T. C. Mineo, E. Pompeo, D. Mineo, F. Tacconi, M. Marino, and A. F. Sabato, "Awake nonresectional lung volume reduction surgery," Annals of Surgery, vol. 243, no. 1, pp. 131-136, 2006.

[131] U. Stammberger, R. Thurnheer, R. A. Schmid, E. W. Russi, and W. Weder, "Redo lung volume reduction surgery in a patient with $\alpha 1$ - antitrypsin deficiency," The Annals of Thoracic Surgery, vol. 69, no. 2, pp. 632-633, 2000.

[132] F. Tacconi, E. Pompeo, D. Forcella, M. Marino, D. Varvaras, and T. C. Mineo, "Lung volume reduction reoperations," The Annals of Thoracic Surgery, vol. 85, no. 4, pp. 1171-1177, 2008.

[133] S. Gasparini, L. Zuccatosta, M. Bonifazi, and C. T. Bolliger, "Bronchoscopic treatment of emphysema: state of the art," Respiration, vol. 84, pp. 250-263, 2012.

[134] Y. Watanabe, K. Matsuo, A. Tamaoki, R. Komoto, and S. Hiraki, "Bronchialocclusion with endobronchial watanabe spigot," Journal of Bronchology, vol. 10, no. 4, pp. 264-267, 2003.

[135] T. P. Toma, K. Matsuo, A. Tamaoki et al., "Endoscopic bronchial occlusion with spigots in patients with emphysema (abstract)," The American Journal of Respiratory and Critical Care Medicine, vol. 165, p. B9, 2002.

[136] F. J. F. Herth, M. Noppen, A. Valipour et al., "Efficacy predictors of lung volume reduction with Zephyr valves in a European cohort," European Respiratory Journal, vol. 39, pp. 1334-1342, 2012.

[137] D. H. Sterman, A. C. Mehta, D. E. Wood et al., "A multicenter pilot study of a bronchial valve for the treatment of severe emphysema," Respiration, vol. 79, no. 3, pp. 222-233, 2010.

[138] W. Mitnzer, "Collateral ventilation," in The Lung: Scientific Foundations, R. G. Crystal, Ed., pp. 1053-1063, Raven Press, New York, NY, USA, 1991.

[139] N. W. Morrell, B. K. Wignall, T. Biggs, and W. A. Seed, "Collateral ventilation and gas exchange in emphysema," The American Journal of Respiratory and Critical Care Medicine, vol. 150, no. 3, pp. 635-641, 1994.

[140] E. Reymond, A. Jankowski, C. Pison et al., "Prediction of lobar collateral ventilation in 25 patients with severe emphysema by fissure analysis with CT,' The American Journal of Roentgenology, vol. 201, pp. W571-W575, 2013.

[141] S. Mantri, C. Macaraeg, S. Shetty et al., "Technical advances: measurement of collateral flow in the lung with a dedicated endobronchial catheter system," Journal of Bronchology, vol. 16, no. 2, pp. 141-144, 2009.

[142] D. Gompelmann, R. Eberhardt, G. Michaud, A. Ernst, and F. J. F. Herth, "Predicting atelectasis by assessment of collateral ventilation prior to endobronchial lung volume reduction: a feasibility study," Respiration, vol. 80, no. 5, pp. 419-425, 2010.

[143] J. Reilly, G. Washko, V. Pinto-Plata et al., "Biological lung volume reduction: a new bronchoscopic therapy for advanced emphysema," Chest, vol. 131, no. 4, pp. 1108-1113, 2007.

[144] F. J. F. Herth, D. Gompelmann, F. Stanzel et al., "Treatment of advanced emphysema with emphysematous lung sealant (AeriSeal)," Respiration, vol. 82, no. 1, pp. 36-45, 2011.

[145] D. J. Slebos, K. Klooster, A. Ernst, F. J. F. Herth, and H. A. Kerstjens, "Bronchoscopic lung volume reduction coil treatment of patients with severe heterogeneous emphysema," Chest, vol. 142, pp. 574-582, 2012.
[146] G. Snell, F. J. F. Herth, P. Hopkins et al., "Bronchoscopic thermal vapor ablation therapy in the management of heterogeneous emphysema," European Respiratory Journal, vol. 39, pp. 13261333, 2012.

[147] C. K. Choong, P. T. Macklem, J. A. Pierce et al., "Airway bypass improves the mechanical properties of explanted emphysematous lungs," The American Journal of Respiratory and Critical Care Medicine, vol. 178, no. 9, pp. 902-905, 2008.

[148] H. F. Lausberg, K. Chino, G. A. Patterson et al., "Bronchial fenestration improves expiratory flow in emphysematous human lungs," The Annals of Thoracic Surgery, vol. 75, no. 2, pp. 393398, 2003.

[149] P. L. Shah, D.-J. Slebos, P. F. G. Cardoso et al., "Bronchoscopic lung-volume reduction with Exhale airway stents for emphysema (EASE trial): randomised, sham-controlled, multicentre trial," The Lancet, vol. 378, no. 9795, pp. 997-1005, 2011.

[150] P. Akuthota, D. Litmanovich, M. Zutler et al., "An evidencebased estimate on the size of the potential patient pool for lung volume reduction surgery," The Annals of Thoracic Surgery, vol. 94, pp. 205-211, 2012.

[151] G. J. Criner, F. Cordova, A. L. Sternberg, and F. J. Martinez, "The National Emphysema Treatment Trial (NETT)_Part II: lessons learned about lung volume reduction surgery," The American Journal of Respiratory and Critical Care Medicine, vol. 184, no. 8, pp. 881-893, 2011.

[152] T. Geiser, B. Schwizer, T. Krueger et al., "Outcome after unilateral lung volume reduction surgery in patients with severe emphysema," European Journal of Cardio-Thoracic Surgery, vol. 20, no. 4, pp. 674-678, 2001.

[153] B. F. Meyers, P. K. Sultan, T. J. Guthrie et al., "Outcomes after unilateral lung volume reduction," The Annals of Thoracic Surgery, vol. 86, no. 1, pp. 204-212, 2008. 


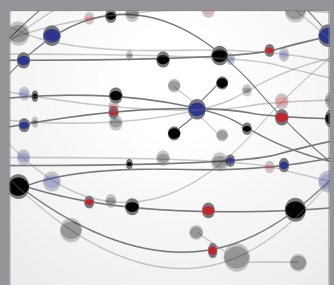

The Scientific World Journal
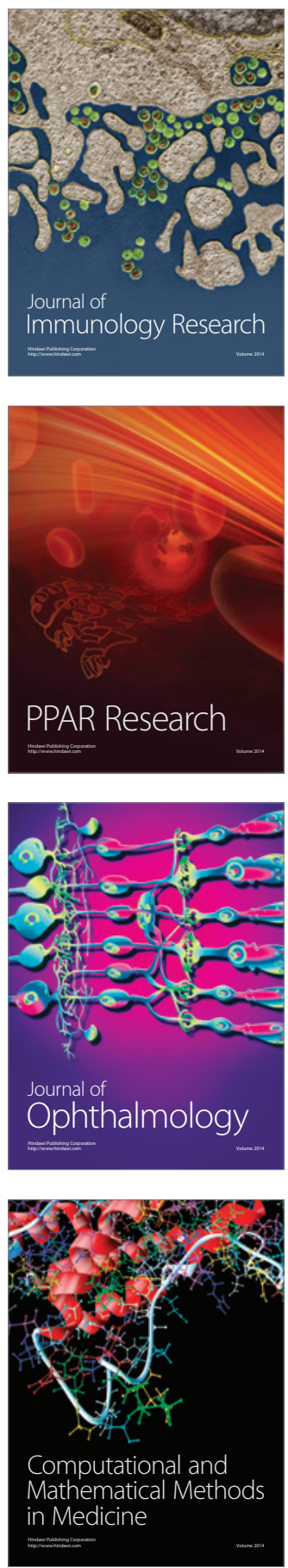

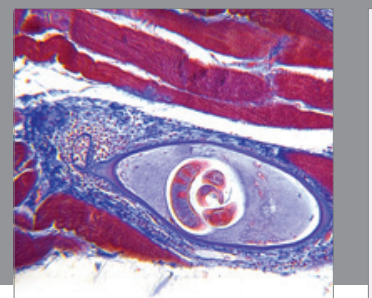

Gastroenterology

Research and Practice
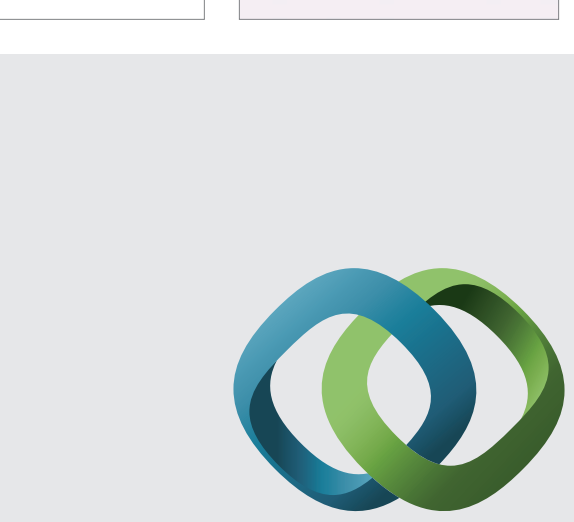

\section{Hindawi}

Submit your manuscripts at

http://www.hindawi.com
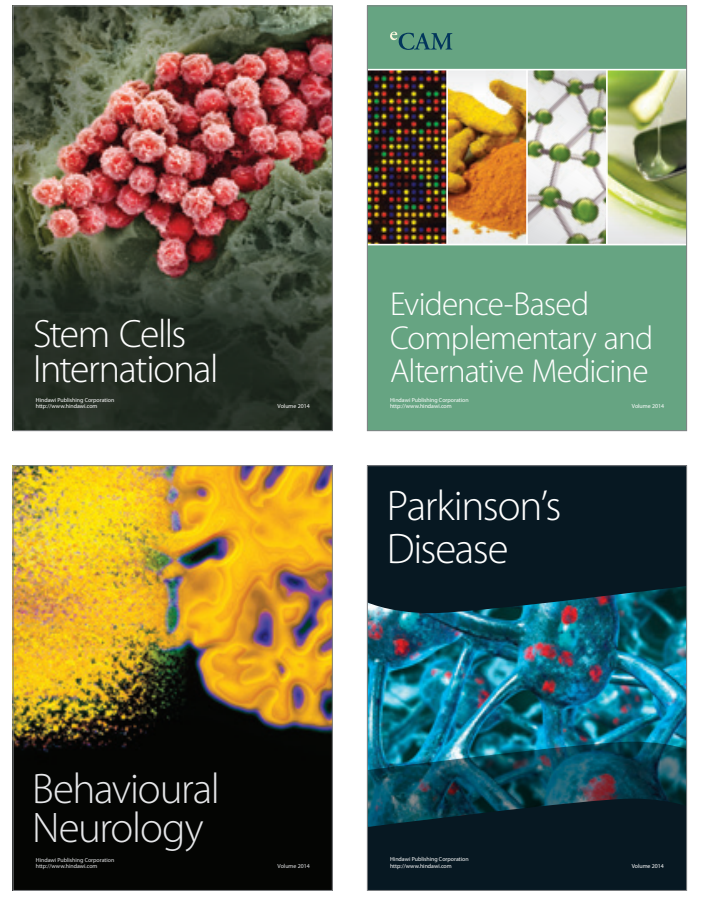
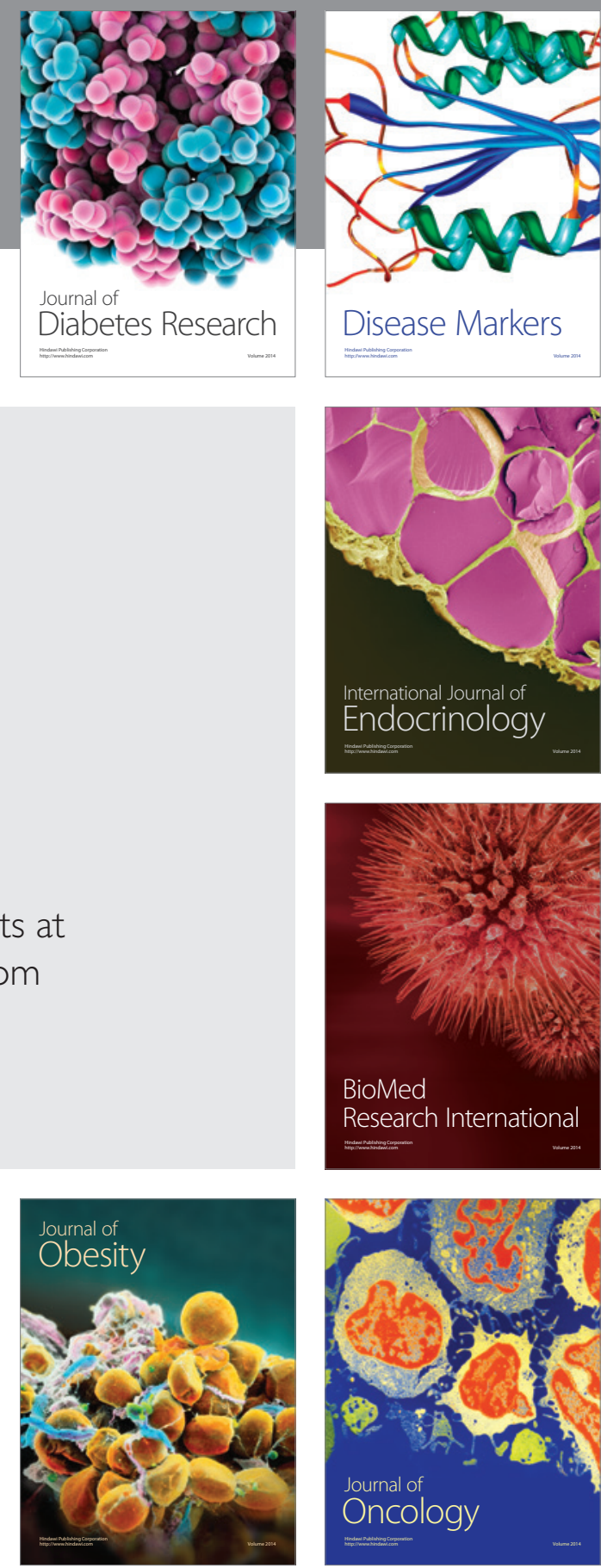

Disease Markers
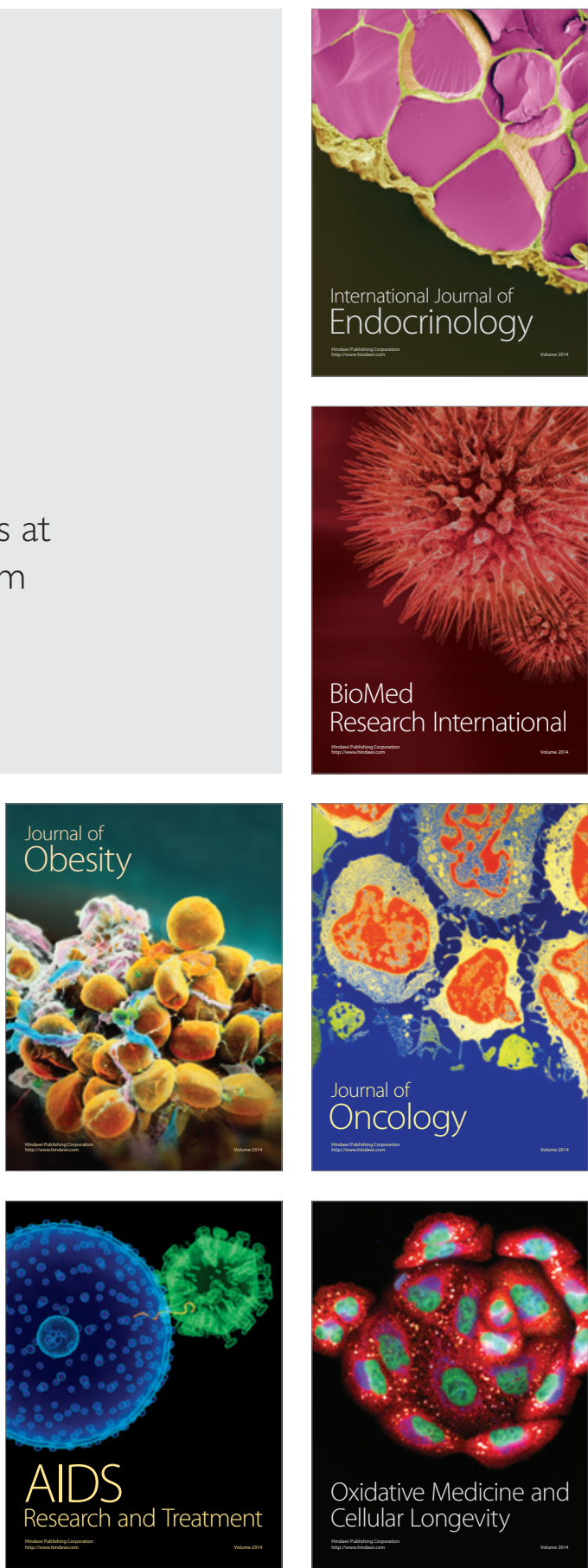